\title{
serie Advertising and Business Cycle Fluctuations
}

\section{Ivie}


Los documentos de trabajo del Ivie ofrecen un avance de los resultados de las investigaciones económicas en curso, con objeto de generar un proceso de discusión previo a su remisión a las revistas científicas. Al publicar este documento de trabajo, el Ivie no asume responsabilidad sobre su contenido.

Ivie working papers offer in advance the results of economic research under way in order to encourage a discussion process before sending them to scientific journals for their final publication. Ivie's decision to publish this working paper does not imply any responsibility for its content.

La Serie AD es continuadora de la labor iniciada por el Departamento de Fundamentos de Análisis Económico de la Universidad de Alicante en su colección "A DISCUSIÓN" y difunde trabajos de marcado contenido teórico. Esta serie es coordinada por Carmen Herrero.

The AD series, coordinated by Carmen Herrero, is a continuation of the work initiated by the Department of Economic Analysis of the Universidad de Alicante in its collection "A DISCUSIÓN", providing and distributing papers marked by their theoretical content.

Todos los documentos de trabajo están disponibles de forma gratuita en la web del Ivie http://www.ivie.es, así como las instrucciones para los autores que desean publicar en nuestras series.

Working papers can be downloaded free of charge from the Ivie website http:/ /www.ivie.es, as well as the instructions for authors who are interested in publishing in our series.

Edita / Published by: Instituto Valenciano de Investigaciones Económicas, S.A.

Depósito Legal / Legal Deposit no.: V-1281-2009

Impreso en España (marzo 2009) / Printed in Spain (March 2009) 


\title{
WP-AD 2009-09 \\ Advertising and Business Cycle Fluctuations ${ }^{*}$
}

\author{
Benedetto Molinari and Francesco Turino ${ }^{* *}$
}

\begin{abstract}
This paper provides new empirical evidence for quarterly U.S. aggregate advertising expenditures, showing that advertising has a well defined pattern over the Business Cycle. To understand this pattern we develop a general equilibrium model where targeted advertising increases the marginal utility of the advertised good. Advertising intensity is endogenously determined by profit maximizing firms. We embed this assumption into an otherwise standard model of the business cycle with monopolistic competition. We find that advertising affects the aggregate dynamics in a relevant way, and it exacerbates the welfare costs of fluctuations for the consumer. Finally, we provide estimates of our setup using Bayesian techniques.
\end{abstract}

Keywords: Advertising, DSGE model, Business Cycle fluctuations, Bayesian estimation, habits persistence.

JEL Classification: D11, E32, J22, M37

\footnotetext{
* This paper was part of our Ph. D. theses at UPF. We are grateful to our advisors, respectively Albert Marcet and Jordi Galí, for their guidance during this period. Also, we wish to acknowledge useful talks and suggestions about this project from David Andolfatto, Alberto Bisin, Andrea Caggese, Pierluigi Ciocca, Fabio Canova, Timothy Kehoe and participants to the Macro Workshop at UPF, the Macroeconomic Workshop in Vigo, and the ASSET 2006 Conference. Finally, Albert Marcet and Ramon Marimon are gratefully acknowledged for the financial support provided to collect the database used in this paper. This database was made possible by the courtesy of the staff of Jonson Graduate School of Management Library (Sage Hall, Cornell University).

** B. Molinari: Universidad Pablo de Olavide (Sevlla, Spain - EU). Contact e.mail: benedetto.molinari@upf.edu. F. Turino, Corresponding author: Departament de Fonaments de l'Análisis Económica, Universitat D'Alacant, Campus de Sant Vicent, Alacant 03080, SPAIN. Telephone: 34-965.903.400 (ext: 3217), Fax: 34-965.903.898. e.mail: fturino@merlin.fae.ua.es
} 
"... as a matter of fact, the scale of expenditures on advertising varies positively with the general level of economic activity, so that, insofar as the effect of marginal expenditures is positive, advertising itself tends to accentuate the amplitude of economic fluctuations..."

Nicholas Kaldor (1950)

\section{Introduction}

In 2005 firms spent 230 billions of dollars to advertise their products in U.S. media, around 1000 dollars per U.S. citizen. Advertising as an industry in U.S. is worth $2.2 \%$ of GDP, absorbs around $20 \%$ of firms' budget for new investments, and $13 \%$ of their corporate profits. ${ }^{1}$ Despite the sizeable amount of resources that it absorbs in the economy, advertising has been traditionally analyzed in microeconomic contexts, receiving scarce attention in macroeconomic literature. Most likely, the reason is that advertising is commonly viewed as a selling cost ${ }^{2}$ that potentially redistributes the demand across firms of the same industry without affecting total market size, and therefore not playing any significative role in macroeconomic theory. ${ }^{3}$

In this paper we take a different stand on this topic, arguing that advertising can have a significant impact on aggregate dynamics once we account for the effect that it is traditionally supposed to have on the demand. As a matter of fact, in the microeconomic literature the rationale of firms spending on advertising has been identified with the positive effect of advertising on sales. Indeed, firms realize that the demand they face is not exogenously given by consumers' preferences, but it can be tilt toward their own products through advertisements. The effectiveness of advertising in enhancing the demand is not only revealed by firm's attitude to spend money on it, but also supported by a large number of empirical studies. ${ }^{4}$ Overall, the positive relationship between firm's advertising and its own demand is widely accepted as robust empirical evidence. Building on this fact, in this paper we ask whether such relationship may hold also in the aggregate. Since the reason of advertising is to increase consumers' demand, targeted advertising increases the sales of a single good, would aggregate advertising enhance aggregate consumption? And, if yes, will it also increase aggregate demand and production through consumption? Moreover, will aggregate advertising affect other aspects of the economy?

We focus on the relationship between advertising and aggregate consumption because this turns out to play a crucial role in order to assess the aggregate impact of advertising. As we will show in section 4, a variation in the level of aggregate consumption due to a variation of aggregate advertising is the main channel for advertising to propagate through the economy. If we shut down this channel, the effect of advertising becomes negligible.

The question whether aggregate advertising is a determinant of aggregate consumption has already been posed in the literature, and a widespread opinion is that the answer should be negative. Building on Solow (1968) and Simon (1970), macro-economists argue that it would be incorrect to assume aggregate advertising and aggregate consumption to have the same causality relationship

\footnotetext{
${ }^{1}$ Statistics refer to 2005. Investment are fixed non-residential investment (source Bureau of Economic Analysis of U.S.). Profits are taken from The Economist (Economic and Financial Indicators).

${ }^{2} \mathrm{~A}$ selling cost is meant a cost that firms bear in order to enhance the demand, but it neither enters as a factor in the production function, like investment in equipment and machinery, nor affects the production technology, like R\&D.

${ }^{3}$ In this perspective advertising is meant to be a combative and dissipative cost. It is interesting to note, however, that in industrial organization literature the idea of advertising as market enhancing mechanism at industry level is widely accepted. See for instance Friedman (1983) or Martin (1993, ch. 6).

${ }^{4} \mathrm{~A}$ survey of this studies can be found in Bagwell (2005) and Schmalensee (1972).
} 
that holds between targeted advertising and sales, since advertising raises firm's demand by stealing customers from competitors, and not by increasing the overall size of the markets. Because of this "competition" effect, advertising would just affect the composition, but not the size of aggregate consumption. In the literature, however, there is also an opposite view that builds on Galbraith (1958), who supported the enhancing effect of advertising on aggregate consumption. As a matter of fact, several papers sought for empirical evidence to settle this debate, among them Ashley, Granger, and Schmalensee (1980), Jacobson and Nicosia (1981), or more recently, Jung and Seldom (1995). However, despite the large amount of empirical studies, the evidence of positive relation between aggregate advertising and consumption is not conclusive, and after the conjectures of those classical economists the literature still lacks of a theoretical framework where to analyze aggregate advertising. ${ }^{5}$

In this paper we attempt to fill this gap by providing a general equilibrium model that accounts for advertising. In particular, we assume a specification of preferences that nests the two competing theories about aggregate advertising, i.e. advertising as market enhancing vs. spread-the demandaround advertising. Then, we use this model to analyze the effect of advertising on aggregate dynamics. The main result of the paper is to show that, under some conditions, advertising can have a quantitatively relevant impact on aggregate dynamics by generating a work and spend cycle: a consumer who wants to spend more on consumption because of the advertising incentive, but faces the intertemporal budget constraint, will end up working more hours. Also, using the DSGE model we precisely identify the conditions under which the responses of consumption and labor to any of the shocks considered are larger when firms are allowed to promote their products by incurring in advertising expenditures. As a result, advertising potentially tends to accentuate the amplitude of the business cycle fluctuations as suggested by Kaldor (1950). We assess the quantitative impact of advertising on fluctuations by measuring the welfare costs of fluctuations when firms are allowed to advertise against the ones of an economy where advertising is banned. Finally, by means of a Bayesian estimation of a log-linearized version of our model, we asses which theory of advertising is more likely to be true conditional on aggregate data. One main result of this paper is to show that aggregate advertising does affect aggregate consumption, as originally suggested by Galbraith (1958).

In this paper advertising is intended as a form of manipulation of consumer's preferences. ${ }^{6}$ As in Dixit and Norman (1978) and Benhabib and Bisin (2002), we model advertising to increase the marginal utility of the advertised good through a modification of parameters in the utility function. Notice, however, that this assumption is not by itself a sufficient condition to conclude that aggregate advertising enhances aggregate demand. If consumers used savings to pay the extra consumption generated by advertisements, then advertising would at the same time increase consumption and crowd out investments, and the net effect on the demand would be unclear. Also, if advertising shifted purchases toward more expensive goods, then an increase in advertising could imply a reduction in real consumption, and therefore in the aggregate demand. Moreover, advertising is not just a matter of demand, it can affect the economic activity in various ways. For instance increasing the substitutability among goods, and therefore affecting the market power of

\footnotetext{
${ }^{5}$ There are some exceptions. Benhabib and Bisin (2002) analyze what are the conditions such that advertising can affect the aggregate labor supply in a neoclassical general equilibrium model, and Grossmann (2007) studies the link between advertising and in-house R\&D expenditures in a quality-ladder model of endogenous Growth.

${ }^{6}$ The way to integrate advertising in consumer's choice theory is controversial. In general, there are three different views in the literature about what advertising does: the Persuasive, the Informative, and the Complementary view. See Bagwell (2005) for an excellent survey. A tastes shifter advertising as the one we model here fits in with the Persuasive view about advertising, as originally proposed by Marshall (1890,1919), Chamberlain (1933), Robinson (1933), Kaldor (1950), and later on used by Dixit and Norman (1978) and Benhabib and Bisin (2002).
} 
firms (price effects). Or, in a dynamic framework, reducing consumers savings, and hence future demand. Overall, the general equilibrium effect of advertising on the economy does not seem obvious. In order to cope with all the effects mentioned above, we embed our candidate utility function with advertising into a dynamic stochastic growth model with monopolistic competition, and we simulate it to analyze the effect of advertising in the general equilibrium solution of the model.

In our model economy advertising affects aggregate dynamics in several ways. It absorbs resources, increases firms' monopolistic power, and in equilibrium raises consumption, labor, and output. Basically, we can identify three channels through which advertising operates on the aggregate dynamics. The first one we refer to as the work and spend cycle: in the presence of advertising, people work more in order to afford a higher consumption path, where the perceived need for higher consumption is due to the advertising signals agents are exposed to. In fact, in this setup consumers' tastes are endogenous, since they depend on firms' optimal advertising policy, and possibly vary over time. The second mechanism operates through prices. Advertising increases firms' markup, therefore reducing consumer's wage and, other things equal, the quantity of labor supplied. The third mechanism operates through the resource constraint. Since advertising absorbs resources, it puts a wedge between gross production and net GDP, which is defined as consumption plus investment. We show that for a reasonable set of parameter calibrations, the first mechanism prevails over the others. In equilibrium both labor and output increase. Then, part of the extra production is used to produce advertising, and the rest is sold as consumption goods.

The way we include advertising in the utility function is akin to that used in the macroeconomic literature on consumption habits. ${ }^{7}$ Like external deep habits, advertising creates dissatisfaction in the consumer about his actual level of consumption, pushing him to buy more. Where advertising differs from habits is that the enhancing effect on the good demand is generated endogenously in the equilibrium by the interaction between firms' decisions and consumers reactions, while in the case of habits it is exogenously assumed. We stress this point because one result in our framework is that the demand of single variety goods turns out to be function of past advertising, which itself is function of past sales. Hence, the demand function of good $i$ can be written as function of past consumption of good $i$, as in models of customer markets or models with "deep habits" preferences.

The paper proceeds as follows. In section 2 we characterize the cyclical behavior of quarterly aggregate advertising expenditures. Section 3 introduces the general equilibrium model with advertising. We show that firms optimally use advertising as a complementary tool to price-setting. As a side contribution of the paper, the dynamic version of the Dorfam-Steiner (1954) theorem is provided. Simulation results are reported in section 4. In section 5, we analyze the welfare implications of the presence of advertising. Finally, we estimate a log-linearized version of the model to test for the effect of advertising on aggregate consumption. The results are reported in section 6 . Conditional on our data, the market enhancing hypothesis is preferred versus the spread-it-around, meaning that advertising does affect aggregate consumption, and through consumption, the labor supply, the markup, and eventually the aggregate production. Section 7 concludes.

\section{Stylized Facts}

In what follows we define aggregate advertising as total spending borne by domestic and foreign firms to advertise their products in U.S. media. Quarterly data of aggregate advertising are

\footnotetext{
${ }^{7}$ See Abel (1990) and Ravn Schmitt-Grohe and Uribe (2006).
} 

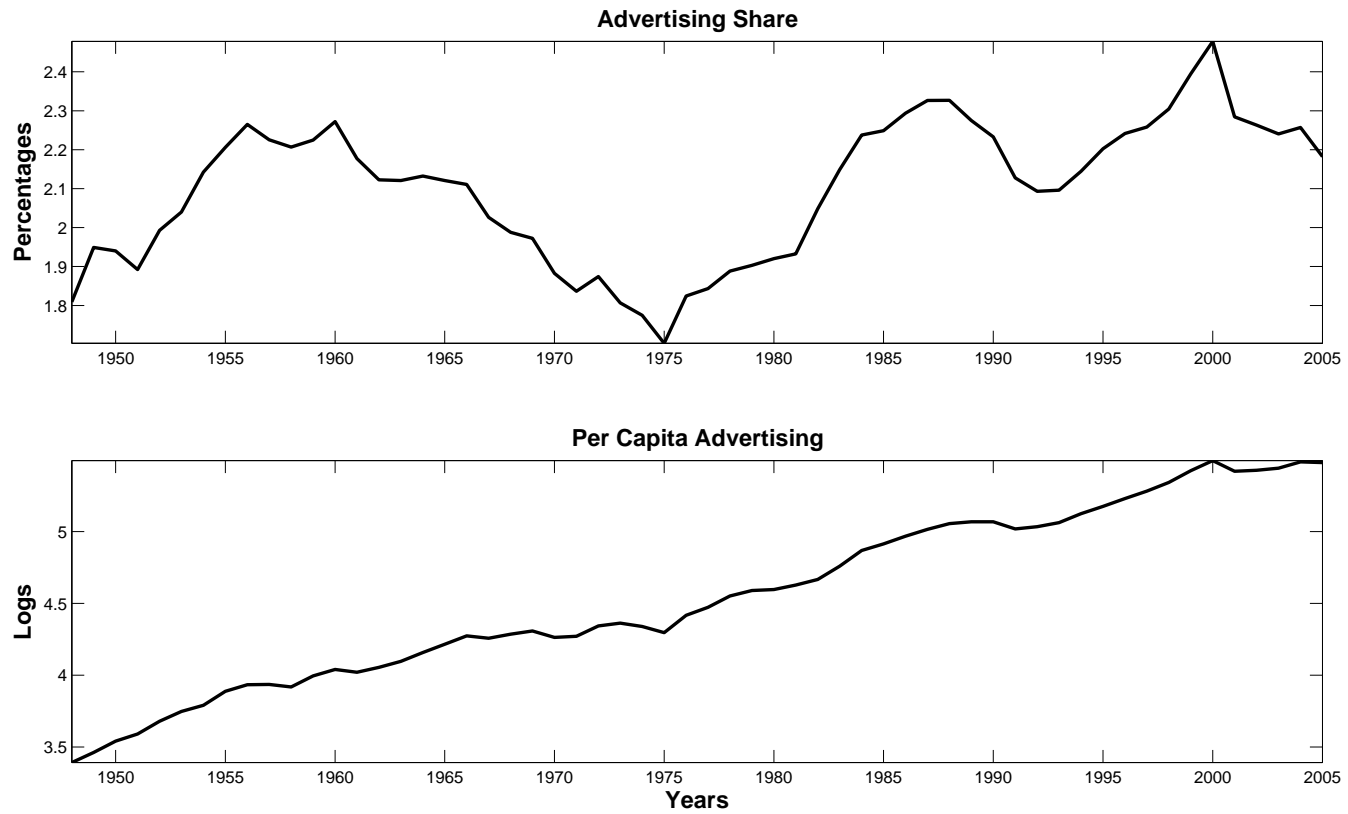

Figure 1: Advertising in Postwar U.S. economy. Panel 1. Advertising as share of GDP. Panel 2. Per-capita real advertising. Coen's annual data, sample from 1948 to 2005.

not included among standard business cycle indicators. We collected them relying on various sources, which are listed in Appendix A. The resulting database that we use in this paper is therefore novel, and up to our knowledge it is the only up-to-date free-of-charge quarterly series of U.S. aggregate advertising available in the literature. ${ }^{8}$ Our data report firms' expenditures on advertising in 7 media, namely: cable and network televisions, radio, newspapers, magazines and Sunday magazines, billboards, direct mails, and outdoor advertising. The sample starts in the first quarter of 1976 and ends the second quarter of 2006, (122 quarters).

In order to check whether the series provided in this paper is actually representative of the whole U.S. aggregate advertising expenditures, we compute the total yearly cumulated expenditures from our data set, and we compare them with the annual data series for total advertising expenditures constructed by Robert Coen of Universal McCann, which is considered by advertising experts the most reliable source of data on aggregate advertising. ${ }^{9}$ For our sample the series we built accounts on average for nearly $30 \%$ of Coen's aggregate advertising, with a minimum of $25 \%$, and an in-sample standard deviation of $2.95 \%$.

Coen's annual data are useful to assess the magnitude of the phenomenon at issue. As we can see from panel 1 of figure (1), the ratio of advertising over GDP fluctuates around $2.1 \%$ throughout the sample, with a peak in the 2000. Overall, the picture shows that advertising is a sizeable industry in the US economy. Also, panel 2 of figure (1) plots per-capita real advertising expenditures. This statistic is commonly used in the literature as measure of the number of advertising messages that reaches the consumer, i.e. a proxy for the intensity of advertising in the

\footnotetext{
${ }^{8}$ U.S. Federal administration used to collect quarterly data of aggregate advertising, but it stopped after 1968, when advertising was dismissed from the list of relevant variables used by the FED to analyze the cycle.

${ }^{9}$ See Appendix A for details on the sources of data.
} 

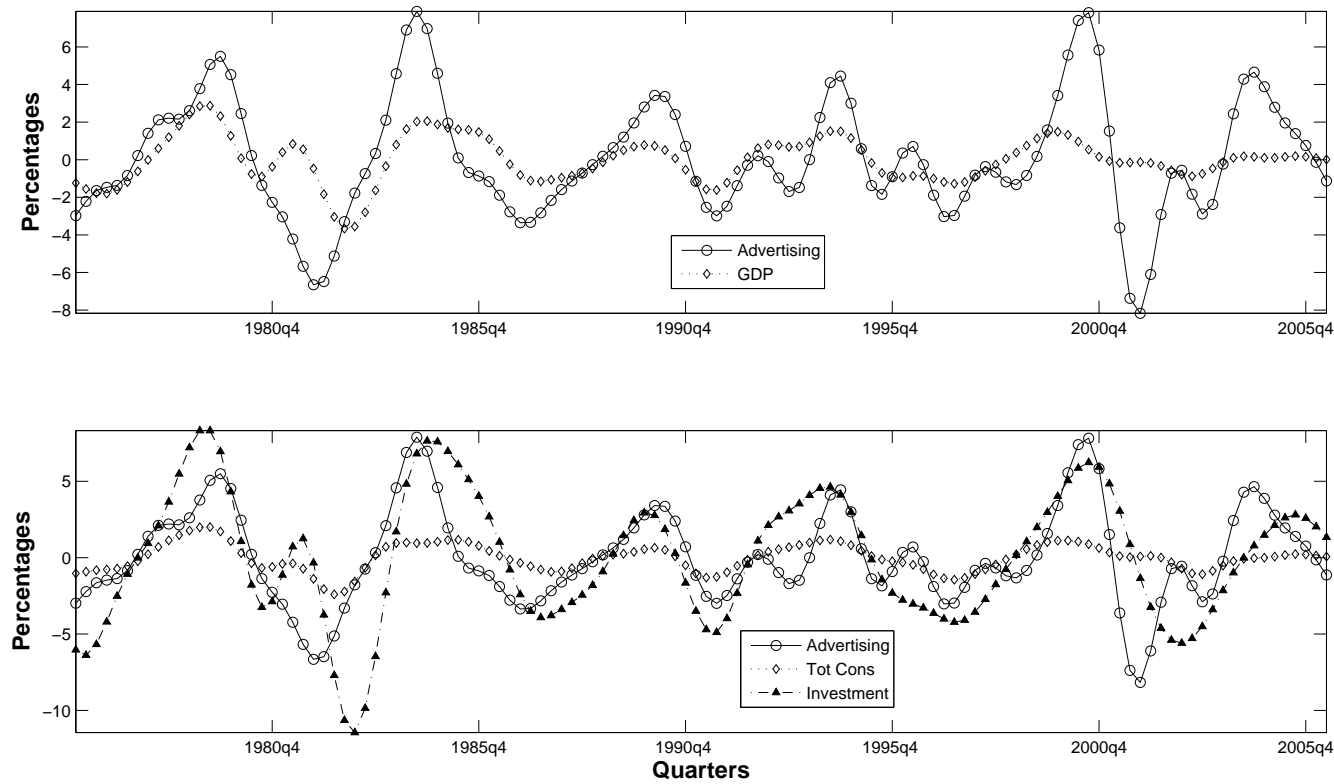

Figure 2: Advertising and the main Business Cycle Indicators. Quarterly figures. Data sample from 1976q1 to 2006q2.

economy. As we can see from panel 2, there is a strong upward trend in per-capita advertising, showing that the number of advertising message per individual has constantly grown over all the second half of the last century.

More interestingly for the purpose of this paper, figure (2) plots quarterly real advertising expenditures along with real GDP, real total consumption, and real fixed private investment. ${ }^{10}$ Basically, it shows that: (i) advertising is pro-cyclical; (ii) it is more volatile than GDP and consumption, and less than investment.

Table 1 reports some related statistics. The overall picture confirms the previous conjecture: advertising is a procyclical and high volatile series. Advertising displays indeed a high and positive correlation with GDP (0.59), and it is 2.62 times more volatile than output. In addition, the point estimate of first order autocorrelation of 0.90 shows that innovations have a persistent effect on advertising expenditures. Also, the positive correlation (0.26) between advertising-GDP ratio and GDP itself suggests that advertising cannot be simply assumed as a constant proportion of output.

Compared with the other aggregates, we note that among the reported series, advertising displays the strongest correlation with total consumption expenditures (0.68). In terms of volatility, advertising features a much higher standard deviation: our point estimates indicate that advertising is 3.64 times more volatile than consumption. In details, advertising is 4 times more volatile than non-durable consumption and slightly more volatile than expenditures in durable goods (the relative standard deviation is equal to 1.12). Finally, we note that advertising is less volatile than

\footnotetext{
${ }^{10}$ All the quarterly figures we use in this section are in logs and in per capita units. In figure (2), the cyclical components have been extracted using a Band Pass (BP) filter with 6-32 as bands. For advertising, we previously wash out the seasonal component present in the raw data using the X11 filter. Also, to control for spurious facts we calculated all the statistics presented in this section both with BP and Hodrick-Prescott filter. The main empirical evidence presented in this section do not change using one or the other filter.
} 
Table 1: Second order moments

\begin{tabular}{l|cccc}
\hline \hline$X_{t}$ & $\frac{\sigma\left(X_{t}\right)}{\sigma\left(G d p_{t}\right)}$ & $\operatorname{corr}\left(X_{t}, A d v_{t}\right)$ & $\operatorname{corr}\left(X_{t}, G D P_{t}\right)$ & $\operatorname{corr}\left(X_{t}, X_{t-1}\right)$ \\
\hline \hline \multicolumn{5}{c}{ Quarterly Data } \\
\hline Advertising & 2.62 & 1 & 0.59 & 0.90 \\
GPD & 1 & 0.59 & 1 & 0.93 \\
Consumption & 0.72 & 0.68 & 0.91 & 0.94 \\
$\quad$ Non-Dur. & 0.60 & 0.67 & 0.79 & 0.93 \\
Durables & 2.33 & 0.60 & 0.90 & 0.92 \\
Investment & 3.41 & 0.64 & 0.93 & 0.94 \\
Adv & 2.18 & 0.93 & 0.26 & 0.88 \\
\hline GDP & \multicolumn{5}{c}{ Annual Data } \\
\hline GDP & 1 & 0.72 & 1 & 0.08 \\
Advertising & 1.62 & 1 & 0.72 & 0.12 \\
Adv & 1.14 & 0.79 & 0.15 & 0.01 \\
\hline GDP & \multicolumn{5}{c}{ G(.) }
\end{tabular}

Note: $\sigma($.$) is in-sample standard deviation. Annual data have been detrended using the \mathrm{BP}(2,8)$

private fixed investment. Indeed, in our sample the standard deviation of advertising is about $23 \%$ lower than the investment one. ${ }^{11}$

Since we have only a partial series of aggregate advertising expenditures, we check the robustness of previous findings by computing the same statistics with Coen's annual data. Results are in the second panel of Table 1. Annual data confirms the quarterly evidence: aggregate advertising is pro-cyclical - $\operatorname{corr}\left(A d v_{t}, G D P_{t}\right)=0.72-$, and more volatile than output $\sigma\left(A d v_{t}\right) / \sigma\left(G D P_{t}\right)=1.62$, as in quarterly data.

As last issue, we analyze the dynamic cross correlations between advertising, consumption, and investment. Dynamic correlations are useful to provide empirical evidence to support or dismiss the idea that advertising can be a leading indicator of the cycle.

As we can see from Table 2, advertising slightly leads GDP, but this evidence is not overwhelming. The cross-correlation coefficient is almost the same at $\mathrm{k}=0$ (0.59) and at $\mathrm{k}=1$ (0.60). Also, advertising appears to move contemporaneously with consumption (i.e. the strongest correlation occurs at $\mathrm{k}=0$ ), while it strongly leads investment (higher correlation occurs at $\mathrm{k}=-2$ and $\mathrm{k}=-1$ ) over the cycle. Overall, the result from the dynamic cross-correlation analysis seem to dismiss the idea that advertising is a leading indicator of the cycle. The fact that advertising slightly leads GDP is possibly due to the fact that it co-moves with consumption, which itself has been shown to slightly lead GDP in the data. ${ }^{12}$

All in all, we can summarize our main findings as follows:

- The amount of resources invested in advertising in the U.S. accounts for roughly $2 \%$ of GDP.

\footnotetext{
${ }^{11} \sigma(a d v) / \sigma(\operatorname{Inv})=0.77$

${ }^{12}$ This evidence is not clear in our data, where the correlation between consumption and output is almost the same at $\mathrm{k}=0$ and $\mathrm{k}=1$, but it has been supported and analyzed in several papers, e.g. Wen (2001) and Wen and Benhabib (2004).
} 
Table 2: Dynamic cross correlations.

\begin{tabular}{l|ccccccccc}
\hline \hline \multicolumn{10}{c}{$\operatorname{corr}\left(\mathbf{X}_{t}, \mathbf{G d p}_{\mathbf{t}+\mathbf{k}}\right)$} \\
\hline $\mathbf{k}$ & $\mathbf{- 4}$ & $\mathbf{- 3}$ & $\mathbf{- 2}$ & $\mathbf{- 1}$ & $\mathbf{0}$ & $\mathbf{1}$ & $\mathbf{2}$ & $\mathbf{3}$ & $\mathbf{4}$ \\
\hline Advertising & 0.01 & 0.20 & 0.38 & 0.52 & 0.59 & 0.60 & 0.55 & 0.47 & 0.38 \\
Consumption & 0.16 & 0.39 & 0.62 & 0.81 & 0.91 & 0.90 & 0.78 & 0.58 & 0.35 \\
Investment & 0.27 & 0.54 & 0.76 & 0.91 & 0.93 & 0.84 & 0.66 & 0.42 & 0.18 \\
\hline \multicolumn{10}{c}{$\operatorname{corr}\left(\mathbf{X}_{t}, \mathbf{A d d} \mathbf{t}+\mathbf{k}\right)$} \\
\hline Consumption & 0.35 & 0.46 & 0.57 & 0.65 & 0.68 & 0.63 & 0.51 & 0.34 & 0.13 \\
\multicolumn{1}{c}{ Non-Dur. } & 0.34 & 0.47 & 0.59 & 0.67 & 0.67 & 0.60 & 0.46 & 0.28 & 0.08 \\
Durables & 0.16 & 0.26 & 0.38 & 0.50 & 0.60 & 0.64 & 0.58 & 0.44 & 0.25 \\
Investment & 0.51 & 0.63 & 0.70 & 0.71 & 0.64 & 0.51 & 0.32 & 0.12 & -0.09 \\
\hline \hline
\end{tabular}

- Advertising is strongly procyclical, and positively correlated with both consumption and investment.

- Advertising is highly volatile: more volatile than GDP, consumption, but less than investment. Also, it is persistent over the cycle.

\section{A DSGE model with Advertising}

In this section we describe our model economy. The market consists of a continuum of differentiated goods produced by monopolistically competitive producers that posses the technology to advertise their products. Advertising is assumed to generate an urge to consume the advertised good. We obtain this effect by introducing advertising as an argument of the utility function that is complementary to consumption. We will extensively support this modeling strategy in section 3.4 .

Then, we embed the modified utility function with advertising into an otherwise standard dynamic stochastic growth model with no nominal or real frictions, and we study the dynamics of this model in reaction to: (i) a shock to the production technology; (ii) a shock to preferences; (iii) a shock to the exogenous government spending; (iv) an idiosyncratic shock to the production of advertising.

\subsection{The household and the role of advertising}

We assume that exists a representative consumer with preferences defined over consumption and hours worked that are described by the utility function:

$$
U\left(\tilde{C}_{t}, H_{t}\right)=E_{0} \sum_{t=0}^{\infty} \beta^{t}\left[\frac{\tilde{C}_{t}^{(1-\sigma)}-1}{1-\sigma}-\xi_{t} \frac{H_{t}^{1+\phi}}{1+\phi}\right]
$$

where $\tilde{C}_{t}$ is a consumption aggregate, $H_{t}$ is the time devoted to work, $\xi_{t}$ is a preferences shock. 
The "composite consumption aggregator" $\tilde{C}_{t}$ defined as follows:

$$
\tilde{C}_{t}=\left(\int_{0}^{1}\left(c_{i, t}+B\left(g_{i, t}\right)\right)^{\frac{\varepsilon-1}{\varepsilon}} d i\right)^{\frac{\varepsilon}{\varepsilon-1}}
$$

where $\varepsilon>1$ is the pseudo-elasticity of substitution across varieties; $g_{i, t}$ is the goodwill associated with good $i$ - the goodwill is meant to represent the stock of firm's advertising accumulated over time -, and $B(\cdot)$ is a decreasing and convex function controlling for the impact of the goodwill on consumer's preferences, satisfying $B(0)=a \geq 0 .{ }^{13}$

Building on Arrow and Nerlove (1962), we model the dynamic effect of advertising by assuming that current and past advertising add up to create the reputation of a good, the producer's goodwill, which is defined as the intangible stock of advertising that affects consumer's utility at time $t$, as shown in (2). The stock of goodwill evolves according to the law of motion:

$$
g_{i, t}=z_{i, t}+\left(1-\delta_{g}\right) g_{i, t-1}
$$

where $z_{i, t}$ is firm's investment in new advertising at time $t, \delta_{g} \in(0,1)$ is the depreciation rate of the goodwill.

We introduce the concept of goodwill because several empirical studies shown that advertising campaigns affect products sales for several periods, an evidence that seems robust across different goods, countries, and time periods. ${ }^{14}$ Accordingly, a formalization of the goodwill as in (3) implies that today sales are likely to be affected not only by current advertising expenditures, but also by past advertising, with an intensity that fades out as time goes by.

In our setup the positive link between goodwill and sales operates through the effect of the goodwill on the marginal utility of each variety. Notice, indeed, that from (2) it follows:

$$
\frac{\partial^{2} \tilde{C}_{t}}{\partial c_{i, t} \partial g_{i, t}} \propto-\frac{1}{\varepsilon}\left(c_{i, t}+g_{i, t}\right)^{\frac{-(1+\varepsilon)}{\varepsilon}} B^{\prime}\left(g_{i, t}\right) \geq 0
$$

where the last inequality comes from the assumption that $B(\cdot)$ is decreasing in $g_{i, t}$. This setup reflects what in the literature is known as the persuasive role of advertising: advertisements create some added value to the good that would not otherwise exist. Accordingly, any good that is advertised is worth more to consumers, as if it were a newly different good. The way we capture this effect is to assume that increases of advertising raise the marginal utility of consumed goods. ${ }^{15}$ One advantage of this modeling strategy is to allow advertising to affect consumer's behavior maintaining a certain analytical tractability when we solve the model.

The rest of the model is standard. We assume that the representative consumer holds one asset, the capital stock $K_{t}$, which is assumed to evolve over time according to the following law of motion:

$$
K_{t}=I_{t}+\left(1-\delta_{k}\right) K_{t-1}
$$

\footnotetext{
${ }^{13}$ It easy to see that the consumption aggregate (2) is a Stone-Geary type non homothetic utility function. Depending on whether the term $B\left(g_{i, t}\right)$ is assumed to be positive or negative, the utility displays a saturation point or a subsistence level of consumption with respect to each variety. In both cases, however, the effect of advertising on the market demand is the same. We will analyze this point in section 3.4

${ }^{14}$ In particular, see Clarke (1976) for an empirical study of the dynamic effects of advertising in U.S., and Bagwell (2005) for a survey.

${ }^{15}$ Our assumption on (2) is in the spirit of the "catching up with the Joneses" hypothesis of Abel (1990), or maybe more appropriately, with the single-good habits version proposed by Ravn Schmitt-Grohe and Uribe (2006). As in the case of external habits, the goodwill acts as a negative externality here, and when it increases it creates dissatisfaction in the consumer about his current level of consumption.
} 
where $I_{t}$ denotes the investment, which is a composite good produced with the following technology:

$$
I_{t}=\left(\int_{0}^{1}\left(i_{i, t}\right)^{\frac{\varepsilon-1}{\varepsilon}} d i\right)^{\frac{\varepsilon}{\varepsilon-1}}
$$

The representative consumer rents whatever capital he owns to firms, and supplies labor services per unit of time. Labor and capital markets are perfectly competitive, with a wage $W_{t}$ paid per unit of labor services, and a rental rate $R_{t}$ paid for unit of capital. In addition, the consumer receives net profits $\Pi_{t}$ from firms and pays lump sum taxes $T_{t}$ to finance the exogenous government spending. Under these assumptions, the representative agent's nominal budget constraint is defined as:

$$
\int_{0}^{1} p_{i, t}\left(c_{i, t}+i_{i, t}\right) d i \leq W_{t} H_{t}+R_{t} K_{t-1}+\Pi_{t}-T_{t}
$$

The utility maximization problem for the representative consumer can be stated as choosing the processes $\tilde{C}_{t}, H_{t}$ in order to maximize the utility function (1) subject to (5) and (7). ${ }^{16}$ Notice that in this framework consumer does not choose over the desired level of goodwill, which enters in the utility function as a parameter with a value that is chosen by firms. ${ }^{17}$ The first order conditions for an interior maximum are:

$$
\begin{gathered}
\frac{\tilde{C}_{t}^{-\sigma}}{P_{t}}=\lambda_{t} \\
\lambda_{t}=\beta E\left\{\lambda_{t+1}\left[R_{t}+\left(1-\delta_{k}\right)\right]\right\} \\
\xi_{t} H_{t}^{\phi}=W_{t} \lambda_{t}
\end{gathered}
$$

where $\lambda_{t}$ is the lagrange multiplier associated with the budget constraint, and $P_{t}$ is the aggregate price index. Equation (9) is the familiar Euler equation that gives the intertemporal optimality condition, while equation (10) describes the labor supply schedule.

Optimality conditions (8), (9), (10) are standard in this type of models. Where our model differs from the standard one is that the consumers' shadow price, $\lambda_{t}$, now depends not only on aggregate consumption but also on aggregate goodwill. Consequently, consumer's decisions about labor and investment are both affected by the level of aggregate advertising. ${ }^{18}$

This mechanism plays a pivotal role to determine the general equilibrium results that we will see in the next section. A Partial Equilibrium analysis of the model is useful to see this. Suppose, for instance, that advertising expenditures increase exogenously for a sufficiently large fraction of firms. Given our assumptions, $\int B\left(g_{i, t}\right) d i$ decreases and, as a consequence, the consumers' shadow

\footnotetext{
${ }^{16}$ To solve the maximization problem it is useful to write the budget constraint in the Lagrangian as function of $\tilde{C}_{t}$, $I_{t}$. Notice that at the optimum the following condition holds $\int_{0}^{1} p_{i, t} i_{i, t} d i=P_{t} I_{t}$ and $\int_{0}^{1} p_{i, t} c_{i, t} d i=P_{t} \tilde{C}_{t}-\int_{0}^{1} p_{i, t} g_{i, t} d i$.

${ }^{17}$ This feature is where our model differs from Becker's (1993) complementary theory of advertising. Following the Persuasive view of advertising, we assume that the agent passively receives advertising signaling, which eventually modifies his preferences, without being aware of the effect of advertising on his utility. On the contrary, in Becker (1993) the agent actively demands advertising about the goods he consumes, since the extra information brought by advertisements increases the utility of consuming that good.

${ }^{18}$ In particular, insofar as $\widetilde{C}_{t}$ has negative first derivative with respect to the aggregate goodwill, then advertising will increase both the level of aggregate consumption and the supply of labor.
} 
price, $\lambda_{t}$, increases. Consider now the labor supply schedule (10). An increase in $\lambda_{t}$ implies that the agent values more his consumption relative to leisure since, for a given wage, the marginal rate of substitution increases. Hence, the labor supply schedule shifts to the right, that is, agents are willing to work more in order to consume more.

The same mechanism also affects the consumers' saving decision. Indeed, since the goodwill is an $\mathrm{AR}(1)$ process (see equation (3)), a purely transitory increase in the aggregate advertising raises both the marginal utility of consumption today, $\lambda_{t}$, and tomorrow, $\lambda_{t+1}$. Thus, given the Euler equation (9), the consumer experiences a different intertemporal elasticity of substitution that obviously affects the saving function. However, while the labor supply unambiguously shifts to the right, the total impact on the saving function is not easily predictable. As we will see in the next section, this precisely depends on the expected dynamic response of the goodwill stock to a shock hitting the economy. In particular, whenever the growth rate of the goodwill is expected to be positive, the consumer will find more convenient to postpone his consumption, since he foresees that in the future his marginal utility will be higher. Conversely, when the growth rate of the goodwill is negative, then the consumer experiences the urge in consumption, and increases his demand of consumption today. ${ }^{19}$

Overall, this analysis suggests that from the stand point of a consumer aggregate advertising can be interpreted as an exogenous state variable that modifies its own supply of both labor and saving. The former by modifying the elasticity to the wage rate, the latter by affecting the intertemporal elasticity of substitution.

\section{$3.2 \quad$ Firms}

There is a continuum of firms indexed $i \in[0,1]$, each producing a differentiated product, which is sold as consumption, investment, or government good.

The optimal demand function of consumption goods is the solution to consumer's problem of minimizing consumption expenditures subject to the aggregate constraint (2). It can be shown that this demand is equal to:

$$
c_{i, t}=\max \left\{\left(\frac{p_{i, t}}{P_{t}}\right)^{-\varepsilon} \tilde{C}_{t}-B\left(g_{i, t}\right) ; 0\right\}
$$

where

$$
P_{t}=\left[\int_{0}^{1} p_{i, t}^{1-\varepsilon} d i\right]^{\frac{1}{1-\varepsilon}}
$$

is the nominal price index.

The demand function (11) is a key relationship in our model. As we anticipated in the previous section, it is increasing in the level of advertising: a positive investment in $z_{i, t}$ increases the stock of goodwill $g_{i, t}$, which in turns decreases $B\left(g_{i, t}\right)$. As result, the marginal utility of $c_{i, t}$ increases (see equation (4)), making the consumer willing to pay more for the same amount of good, or equivalently, willing to buy more for any given price. Accordingly, the demand function (11) shifts to the right.

Thus, advertising acts in this model as a demand shifter that increases products sales. The prediction of a positive relationship between sales and advertising is in line with a large number

\footnotetext{
${ }^{19}$ The mechanism is akin with the one that characterizes the effect of an exogenous taste shock.
} 
of empirical studies about advertising at the firm level. ${ }^{20}$ In our setup such a positive relationship crucially depends on the assumption that advertising is an argument of the utility function. It is worth noticing, however, that this assumption is not arbitrary once we restrict our attention to models with Walrasian demand functions and perfect information. In this case the only way advertising can enhance the demand is through a modification of the preference relation. ${ }^{21}$

In this setup advertising not only enhances the demand, but also diminishes its price elasticity, which now is time varying and decreasing in the level of goodwill. In particular, according to (11) the demand function is composed by two terms: the first one, $\left(P_{i, t} / P_{t}\right)^{-\varepsilon} \widetilde{C}_{t}$, with elasticity $\varepsilon$, and the second one, $B\left(g_{i, t}\right)$, which is inelastic. As a consequence, the price elasticity of demand is a weighted average between the elasticity of those two terms, and its value will depend on the relative importance of the goodwill over the total demand, i.e.

$$
\eta\left(c_{i, t}, g_{i, t}\right)=\left|\frac{\partial c_{i, t}}{\partial p_{i, t}} \frac{p_{i, t}}{c_{i, t}}\right|=\varepsilon\left(1+\frac{B\left(g_{i, t}\right)}{c_{i, t}}\right)
$$

In particular, notice that the elasticity of demand (13) is smaller than the elasticity of demand without advertising, i.e. with $g_{i, t}=0 .{ }^{22}$ The finding is a well know effect in the literature, that is, through advertising a firm attempts to develop consumers' loyalty to its own product. The intuition behind this mechanism is that advertising, although it does not modify the quality of the advertised good, nonetheless increases the differentiation among goods perceived by the consumers. Using advertisements the firm can manipulate the elasticity of the demand, thus increasing its market power, and eventually profits. ${ }^{23}$

Contrary to consumption, the demand functions for investment and government goods are standard ${ }^{24}$ since advertising is assumed not to affect either the technology to combine single variety goods into a unit of capital, or government purchases of goods. The first assumption fits naturally into our setup because advertising is assumed to affect consumption, while investment represents here the alternative option for the agent that wants to postpone consumption in the future. So, any enhancing effect of advertising on investment goods would have an ambiguous interpretation, since it would diminish the willingness of the agent to consume, while advertising in this setup is assumed to foster consumption. The second assumption about government purchases may appear arbitrary, though. However, it can be shown that modeling a positive effect of advertising on

\footnotetext{
${ }^{20} \mathrm{~A}$ positive relationship between advertising and sales is one of the few non-controversial empirical evidence about advertising. See Bagwell (2005), section 3.2, for more references.

${ }^{21}$ The argument goes by contradiction. Suppose that advertising shifts the demand, i.e. the consumer chooses two different bundles of goods pre and post advertising, and that the preference relation remains unchanged. Also, recall that advertising is assumed neither to be a productive factor, nor to affect the production technology. Consequently, advertising does not change the quality of the goods, implying that pre and post advertising the consumer is choosing his preferred bundle among the same basket of goods. Moreover, the assumptions that advertising does not affect the production function, so the marginal cost, and that there is perfect information among all the agents, rule out any direct effect of advertising on prices. In this case, after the advertising signal we would have that the consumer chooses a different bundle of goods than before, but that this bundle should have been affordable before the advertising signal. Now, since the preference relation is unchanged, such bundle yields lower utility than the one chosen pre advertising. As result, post advertising the agent is choosing a bundle which is not preferred to the pre advertising one, violating the Weak Axiom of Revealed Preferences. Hence, if the bundle chosen by the agent before and post advertising changes, then also the preference relation must change, which justifies the assumption of advertising as an argument of the utility function. However, this argument does not hold true if we consider models with Walrasian demand correspondences instead of functions. Therefore, preference relation in this model must always be strictly convex.

${ }^{22}$ This occurs because $B\left(g_{i, t}\right)$ is decreasing in $g_{i, t}$.

${ }^{23}$ The link between advertising and price elasticity reveals another important mechanism inherent to our model, i.e. a positive effect of advertising on firms' markup, and therefore on prices.

${ }^{24}$ These demands are derived in Appendix B.
} 
government expenditures would strengthen the effect of advertising on aggregate dynamics, and therefore we can take it as a conservative assumption with respect to the results we find in this paper.

Altogether, the demand for consumption, investment, $i_{i, t}$, and government expenditures, $f_{i, t}$, forms the total demand of firm $i$ at time $t$, i.e.:

$$
y_{i, t} \equiv c_{i, t}+i_{i, t}+f_{i, t}=\left(\frac{p_{i, t}}{P_{t}}\right)^{-\varepsilon}\left(\tilde{C}_{t}+I_{t}+F_{t}\right)-B\left(g_{i, t}\right)
$$

Firm $i$ will choose a price for sales and a level of advertising in order to maximize the discounted flow of future profits subject to the constraint given by the total demand. The optimal policy rules are derived formally in Appendix B. We report them here:

$$
\begin{gathered}
p_{i, t}=\frac{\varepsilon\left(1+\frac{B\left(g_{i, t}\right)}{y_{i, t}}\right)}{\varepsilon\left(1+\frac{B\left(g_{i, t}\right)}{y_{i, t}}\right)-1} \varphi_{t} \equiv \mu_{i, t} \varphi_{t} \\
-\left(p_{i, t}-\varphi_{t}\right) B^{\prime}\left(g_{i, t}\right)+E_{t}\left[\left(1-\delta_{g}\right)\left(\nu_{i, t+1} r_{t, t+1}\right)\right]=\nu_{i, t}
\end{gathered}
$$

where $\varphi_{t}$ is the marginal cost of production, and $\nu_{i, t}$ is the marginal cost of producing new advertising $z_{i, t}$.

Equation (14) describes the familiar pricing policy in monopolistic competition models. The firm exploits its monopolistic power by charging a positive markup $\left(\mu_{i, t}\right)$ over the marginal cost. However, differently from the standard case, the markup in (14) is not fixed but varies in time according to the evolution of the goodwill stock, which affects the price elasticity of demand as we showed in equation (13).

Equation (15) is the firm's optimal advertising policy. It states that a firm invests in advertising until the marginal benefit from an extra dollar of advertising equals the marginal costs of producing it. Given the dynamic nature of the goodwill, the marginal benefit has two components: the increase in current revenues associated with a marginal increase in advertising, and the discounted opportunity cost of not producing tomorrow the surviving goodwill produced today. It is possible to go a bit further and show that equation (15) implies an optimal rule for the goodwill intensity (i.e the ratio of goodwill stock to total sale). In particular, we get a result of the following form.

Proposition 1. Suppose that firm i's demand function is defined as in (11). Let $\eta_{g, t}(i)$ and $\eta_{p, t}^{*}(i)$ respectively denote the gross elasticity of demand with respect to the goodwill stock and the net elasticity of demand with respect to the price. Then, for any firm $i$ the optimal goodwill intensity is proportional to the ratio $\eta_{g, t}(i) / \eta_{p, t}^{*}(i)$.

Proof. To prove the proposition, notice first that from the demand function (11) it follows:

$$
-B^{\prime}\left(g_{i, t}\right)=\eta_{g, t}(i) \frac{y_{i, t}}{g_{i, t}}
$$

where $\eta_{g, t}(i)$ denotes the firm $i$ 's demand elasticity with respect to the goodwill stock. Using this result into (15) to substitute out $B^{\prime}\left(g_{i, t}\right)$ and rearranging the resulting equation yields:

$$
\frac{g_{i, t}}{y_{i, t}}=\eta_{g, t}(i)\left\{\frac{p_{i, t}-\varphi_{t}}{\nu_{i, t}-E_{t}\left[\left(1-\delta_{g}\right)\left(\nu_{i, t+1} r_{t, t+1}\right)\right]}\right\}
$$


or, by substituting out price using its optimal rule (14):

$$
\frac{g_{i, t}}{y_{i, t}}=\frac{\eta_{g, t}(i)}{\eta_{p, t}^{*}(i)} \Omega_{t, i}
$$

where $\Omega_{i, t}=\frac{\varphi_{t}}{\nu_{i, t}-E_{t}\left[\left(1-\delta_{g}\right)\left(\nu_{i, t+1} r_{t, t+1}\right)\right]}$ and $\eta_{p, t}^{*}(i)=\left(\eta\left(y_{i, t}, g_{i, t}\right)-1\right)$ is the net demand price elasticity. Accordingly, the optimal goodwill intensity is proportional to the ratio $\eta_{g, t}(i) / \eta_{p, t}^{*}(i)$.

Notably, the proposition shows that we can establish an equivalence result between our optimal advertising policy and the Dorfman-Steiner (1954) theorem. In particular, under the simplificative assumptions of goodwill stock with total depreciation $\left(\delta_{g}=1\right)$ and common technology in the production of goods and advertising, we get the standard Dorfman-Steiner result, that is, the optimal budget for advertising expenditures is equal to the ratio between the elasticity of the demand with respect to advertising over the elasticity of demand with respect to the price.

The optimal advertising policy is also useful to understand the determinants of advertising itself. According to (15), advertising is sensitive both to variations to supply and demand conditions. On the one hand, reductions in marginal costs lead to higher investments in advertising. On the other hand, the marginal benefit of advertising depends on the markup, which in turns is positively affected by aggregate demand (see equation 14). Therefore, any exogenous increase in the latter increases the markup and raises, at the same time, the optimal level of advertising.

Besides, notice that the markup itself is increasing in the level of goodwill. So, when advertising increases the markup also increases. In fact, in this framework advertising and price setting are complementary policies, in accordance with the theory of optimal advertising as the outcome of firms playing a supermodular game, as shown in Tremblay (2005). ${ }^{25}$

Interestingly, from the optimal advertising policy (15) one can show that advertising generates persistence in the dynamics of consumption, since in equilibrium (16) implies that the demand function (11) depends on past sales as in models with habits in consumption, or in models of customers markets. ${ }^{26}$ Notice, indeed, that equation (16) can be written as:

$$
g_{i, t}=\Phi_{t} y_{i, t}
$$

which shows that in this model each firm invests in advertising a proportion $\Phi_{t}$ of sales, with a time varying coefficient that depends, in particular, on the marginal cost of production and advertising. Now, using (17) lagged one period to work out $g_{i, t-1}$ from the law of motion of goodwill (3), and using the resulting equation to work out $g_{i, t}$ in the demand function (11), we obtain:

$$
y_{i, t}=\left(\frac{p_{i, t}}{P_{t}}\right)^{-\varepsilon}\left(\widetilde{C}_{t}+I_{t}+F_{t}\right)+\psi\left(\Phi_{t}, y_{i, t-1}, z_{i, t}\right)
$$

where $\psi(\cdot)$ is a non linear function with non negative partial derivative with respect to the last two arguments. ${ }^{27}$ As a result, equation (18) shows that demand faced by individual producers depends

\footnotetext{
${ }^{25}$ Also, notice that in the extreme case where advertising has no effect on the demand, (i.e. $\left.B^{\prime}(\cdot)=0\right)$, then equation (15) implies that optimal advertising is equal to zero. Therefore, in this framework the only incentive for firms to advertise is to manipulate the demand. In particular, no strategic reason, as for instance entry deterrence is taken into account here.

${ }^{26}$ About this issue, see Ravn, Schmitt-Grohé and Uribe (2006), and the "habit persistence" entry of Palgrave Economic Dictionary, written by Schmitt-Grohé and Uribe (2006).

${ }^{27}$ This follows immediately from the fact that $B(\cdot)$ is assumed to be strictly decreasing together with the fact that non negative optimal advertising requires $\Phi_{t}>0$.
} 
on past sales. This result is driven from two properties of our setup: (i) the assumption that consumer's preferences are affected by advertising; (ii) the dynamic nature of goodwill. Compared with competing models that explained consumption persistence in the literature, the relevance of our result hinges on the fact that consumption persistence with advertising is endogenously determined in equilibrium, and not exogenously assumed as, for instance, with habits persistence.

Equation (18) reveals that, for a consumer, advertising effort of each individual firms is a demand shifter that resembles an exogenous taste shock. In the aggregate, this potentially provides another channel through which exogenous innovations are transmitted to the economy. The effect of a technology shock is particularly interesting. Suppose, for instance, that the economy experiences an unanticipated increase in productivity. In this model, in addition to all the other traditional mechanisms, a firm will also revise its own advertising policy. In particular, equation (15) indicates that a positive technology shock leads to a higher level of firm's desired goodwill. According to (18), this also implies an upward shift in the aggregate demand. In other words, after a technology shock the level of the aggregate demand will increase instantaneously, not only because of the traditional channels but also because with advertising for any give price the consumer is willing to buy more goods. This result explains why in next section we find that the responses of consumption and labor to a technology shock are, under some specific conditions, larger and more persistent than in the benchmark model without advertising. Since in the literature it has been often noticed that technology shocks cannot generate a business cycle as the one observed in the data, we argue that a stronger internal propagation mechanism, as the one that occurs with advertising, can possibly help to reconcile the business cycle theory with the data. ${ }^{28}$.

\subsection{The Symmetric Equilibrium}

In this model factor markets are perfectly competitive and firms share all the same production technology. Thus, they all face the same marginal cost. ${ }^{29}$ Moreover, all firms face the same gross elasticity of substitution among goods $\varepsilon$. These two conditions jointly imply that there exists a symmetric equilibrium where all firms set the same price, produce the same quantities, and invest the same amount of resources in advertising. ${ }^{30}$ In addition, in each period the equilibrium (common) price of goods is normalized to unity, i.e. $p_{t}=1 \forall t$. So, all the other prices (e.g. wage, rental rate) are expressed in terms of contemporaneous consumption.

Let $X_{t}$ to be the vector of all endogenous variables, ${ }^{31}$ then the symmetric equilibrium for this model is a process $\left\{X_{t}\right\}_{t=0}^{\infty}$ that satisfies: (8)-(10), (14)-(15), plus the production function of consumption goods and advertising, the optimal factors demand for these productions, ${ }^{32}$ the law of motion of capital (5) and the one of goodwill (3), the market clearing condition on the goods market, $Y_{t}=C_{t}+I_{t}+F_{t}$, and the market clearing condition on the labor market, $H_{t}=H_{p, t}+H_{a, t}$.

\subsection{Advertising in Utility Function: Functional Forms Assumptions}

In order to fully specify the utility function we need to parameterize the function $B(\cdot)$ in a way that satisfies all the specific requirements we have assumed so far. In addition, we are interested in an appropriate specification that allows us to nest in the model the two competing theories of advertising: market enhancing and spread-it-around hypothesis. The advantage of this strategy is

\footnotetext{
${ }^{28}$ In particular, in section 6 we use a variance decomposition from the estimated model to show that technology shocks are able to explain a considerable part of the volatility of consumption and output observed in actual data

${ }^{29}$ The reader can check that inspecting the RHS of equation (26).

${ }^{30}$ Assuming also that the initial goodwill stock is common across the firms.

${ }^{31}$ Specifically, $X_{t}=\left(\lambda_{t}, G_{t}, \mu_{t}, Z_{t}, H_{t}, H_{a, t}, H_{p, t}, C_{t}, K_{t}, I_{t}, Y_{t}, R_{t}, W_{t}, Q_{t, t+1}\right)$.

${ }^{32}$ See Appendix B for details.
} 
that it will allow us not to take a stand on these different views, but to leave the data to choose which theory is more likely to be true (conditional on macroeconomic data). It worths stressing again this point because it is crucial to assess the effects of advertising on the aggregate economy. Indeed, as we said in the introduction, if advertising enhances the single-good demands because it steals customers from competitors, then it has no direct effect on aggregate consumption, which in turns implies that in the aggregate advertising only absorbs resources without affecting in a significant way any other macroeconomic variable. On the contrary, if advertising increases the market size for a good without decreasing other goods demand of the same amount, then it turns out to affect in a potentially significant way the level of aggregate consumption and, through this channel, all other aggregate variables, like labor, output and prices.

Therefore, hereafter we assume that the function $B\left(g_{i, t}\right)$ is defined as follows:

$$
B\left(g_{i, t}\right) \equiv S\left(g_{i, t}\right)+\gamma \int_{0}^{1}\left(1-S\left(g_{i, t}\right)\right) d i \text { with } \gamma \in[0,1]
$$

where

$$
S\left(g_{i, t}\right) \equiv \frac{1}{1+\theta g_{i, t}}
$$

One can easily verify that (19) is a strictly decreasing and a convex function of the goodwill stock. More importantly, we can see that in (19) the goodwill enters in quasi-difference from its aggregate mean value, meaning that the effect of a firm $i$ 's advertising on its own demand will also depends on the level of advertising expenditures of all the other competitors. ${ }^{33}$ In the symmetric equilibrium this implies:

$$
B\left(G_{t}\right) \equiv \frac{1+\gamma \theta G_{t}}{1+\theta G_{t}}
$$

Now, when $\gamma=1$, the aggregate goodwill does not enter in the marginal utility of consumption (see equations (8) and (2)). So, it does not affect directly the representative consumer's decisions about labor supply (9) and saving (10). As a consequence, advertising does not affect directly the aggregate consumption demand, i.e. the spread-it-around hypothesis holds.

In this case the effects of the aggregate advertising on the economic activity are easily predictable. It absorbs resources without enhancing the demand, and it has no direct price effects. Thus, it is a deadweight loss both for firms and consumers. However, notice that firms will still be employing resources to advertise their products because in the non cooperative solution they do not internalize the effect of their decisions on the market mean level of advertising. As a consequence, they keep wasting money in an unproductive factor, while the effect of their advertisements on the demand functions is offset by other firms' advertising.

Differently, when $\gamma=0$ the goodwill enters in level in the utility function. Accordingly, firm's $i$ advertising affects the marginal utility of $c_{i, t}$, and in turn shifts upward the demand function of good $i$, no matter what the other firms do. In this case advertising directly affects aggregate consumption, labor, and firms' markup. Finally, any value of $\gamma \in(0,1)$ implies a convex combination between the two extreme cases (complete spread-it-around vs. market enhancing).

A consideration apart deserves the choice of $S(\cdot)$. Equation (20) implies that the marginal utility of consumption is bounded (for this reason we might refer to it as "bounded marginal utility"). ${ }^{34}$ In fact, in the demand function of good $i$ there exists a maximum price above which

\footnotetext{
${ }^{33}$ This formulation implies that advertising is combative.

${ }^{34}$ As a matter of fact, preference featuring bounded marginal utility have been already used in the literature. See for instance Melitz and Ottaviano (2008)
} 
the demand is zero, due to the bound we impose on the marginal utility of consumption. When the price is too high the marginal benefit of consuming that good is smaller than its cost, and the consumer drops it from his basket of purchases.

In the absence of advertising the bound is 1 in every period, whereas in presence of advertising the value of the bound depends on the level of goodwill. In particular, the incentive for firms to advertise is the effect of the goodwill in reducing the bound, which implies that the consumer is willing to pay a higher price for the advertised good. Finally notice that the effect of the goodwill is bigger the higher is $\theta$, which therefore can be interpreted as a measure of the effectiveness of advertising in manipulation consumer's tastes.

\section{Impulse-Response Analysis}

In what follows we refer to a log-linear approximation of model's policy functions in the neighborhood of the non-stochastic steady state. Rational expectations are solved to obtain the dynamic responses of endogenous variables as function of the state variables. We characterize the response of model's variables to several exogenous shocks, namely: a technology shock (figure 3), a preferences shock (figure 4), a shock on the exogenous government spending (figure 5), and an idiosyncratic shock to the advertising production function (figure 6).

To compute the impulse-response functions (IRFs), we require values for the model' structural parameters: $\left[\beta, \sigma, \phi, \Xi, \varepsilon, \theta, \alpha, \rho_{z}, \rho_{a}, \rho_{f}, \rho_{h}, \sigma_{h}, \sigma_{a}, \sigma_{f}, \delta_{g}, \delta_{k}, \gamma\right]$. Much of them are standard for which it has been used common values. In particular, the discount parameter $\beta$ is set to $(1.04)^{-.25}$, implying a yearly nominal interest rate of about $4 \%$. The depreciation rate of capital $\delta_{k}$ is equal to $2.5 \%$ per quarter, and the gross elasticity of substitution across varieties equal to 6. These values are standard in the Business Cycle literature. Following Prescott (1986), we set the preference parameter $\Xi$ to ensure that in the non stochastic steady state, households devote 1/4 of their time to labor activities. Following Ravn, Schmitt-Groh and Uribe (2006), we set the intertemporal elasticity of substitution to 0.5 , the labor elasticity of output, $\alpha$, to 0.75 , the Frisch elasticity of labor supply to 1.3 , and the government expenditures-GDP ratio, $s_{f}$, to 0.12 . These restrictions imply that the preference parameters $\sigma$ and $\phi$ are, respectively, 2 and 0.77 , and the steady state labor share is $0.71 .^{35}$

Values for the advertising related parameters have been assigned using the following strategy. The goodwill depreciation rate has been fixed to 0.3 , implying that the half life of the goodwill stock is about two quarters. This value is consistent with the empirical evidence provided in Clarke (1976), such that the effect of advertising on the firm's demand vanishes after roughly one year. As a benchmark case, we set the parameter $\gamma$ to zero, while the intensity of advertising in the preferences, $\theta$, is chosen such that, conditional to all the other parameters, the steady-state advertising-GDP ratio is equal to $2.27 \%$. This value is consistent with the US average over the period 1948-2005. ${ }^{36}$

The autoregressive parameter for all the endogenous process have been set to 0.95 . This number

${ }^{35}$ In our framework the steady state labor share, denoted by $s_{h}$, takes the following form:

$$
\begin{aligned}
s_{h} & =\frac{W\left(H_{p}+H_{a}\right)}{Y} \\
& =\alpha \mu^{-1}\left[1+\frac{H_{a}}{H_{p}}\right]
\end{aligned}
$$

so that, the usual relation between the intensity of labor in the production function and the labor share is not anymore guaranties. Notice that, in the last equation $\mu$ denotes the average long run markup.

${ }^{36}$ This number refers to the ratio of advertising expenditures to GDP net of exports. 
Table 3: Calibration

\begin{tabular}{ccl}
\hline \hline Parameter & Value & Description \\
\hline$\beta$ & .9902 & Subjective discount factor \\
$\varepsilon$ & 6 & Elasticity of substitution across varieties \\
$\delta_{k}$ & 0.025 & Capital depreciation rate \\
$\Xi$ & 2.49 & Steady State of the preference shock \\
$\delta_{g}$ & 0.3 & Goodwill depreciation rate \\
$\phi$ & 0.77 & Preference parameter \\
$\theta$ & 2.54 & Intensity of advertising in the utility function \\
$\alpha$ & 0.75 & Labor elasticity of output \\
$\sigma$ & 2 & Preference parameter \\
$s_{f}$ & 0.12 & Government expenditures-Gdp ratio \\
$\rho_{a}, \rho_{h}, \rho_{g}, \rho_{z}$ & 0.95 & Persistence of exogenous shocks \\
$\sigma_{a}$ & $7.9 e-3$ & Standard error of the technology shock \\
$\sigma_{f}$ & $9.8 e-3$ & Standard error of the government spending shock \\
$\sigma_{h}$ & $6.2 e-3$ & Standard error of the preference shock \\
\hline \hline
\end{tabular}

is intermediate among the values normally used in the Business Cycle literature. For the simulated exercise, following Rebelo and King (1998) and Collard (2006), we set the standard deviation of technology shock, $\sigma_{a}$, and government expenditures shock, $\sigma_{f}$ to, respectively, 0.0079 and 0.0089 . Finally, the standard deviation of the preference shock, $\sigma_{h}$, is chosen such that the volatility of hours worked in the model matches its empirical counterpart of $0.91 \% .{ }^{37}$ Time period in the model is a quarter. Table 3 summarizes the set of calibrated parameters.

We plot the IRFs for different values of the spread-it-around parameter $\gamma$, and we use the associated model economy where advertising is banned as benchmark to evaluate the impact of advertising.

A number of results are worth emphasizing. First, we note that advertising responds positively to any of the shocks considered. A first explanation of such a result comes directly from equation (17), since it implies a positive relation between aggregate goodwill and aggregate demand. Hence, the latter provides an upward pressure to the goodwill stock whenever it increases as a consequence of a particular shock. This occurs because, at firm level, optimal goodwill is positively related to its marginal benefit which, in turns, depends on the demand. In addition, this explains why advertising reacts positively to both preferences (Figure (4)) and government (Figure (5)) shocks. However, out of the shocks considered, we note that advertising reacts strongly whenever the shock affects directly productivity. For instance, with a positive technology shock (see Figure (3)) the advertising impact response is more than two times bigger that the one with a preference shock. This occurs because when the economy experiences an unexpected increase in productivity, a firm revises its own advertising policy not only because of different demand condition but also because advertising becomes instantaneously more efficient. In addition, the dynamic nature of advertising

\footnotetext{
${ }^{37}$ This number refers to the standard deviation of the bandpass filtered hours worked in our sample.
} 

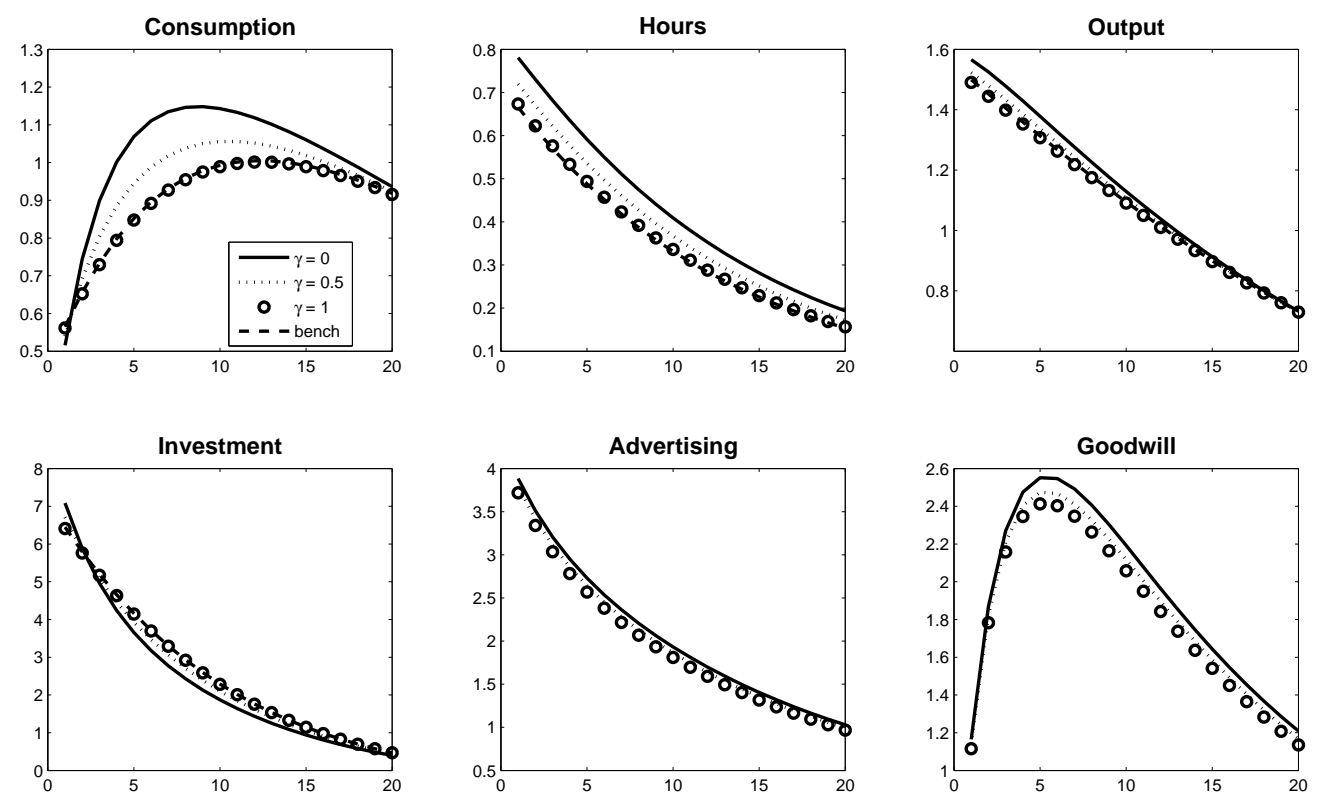

Figure 3: Impulse Response Functions to technology shock. Each plot displays percent deviation from steady state of the corresponding variable in response to a $1 \%$ increase in the rate of productivity.

amplifies this effect by making the incentive to invest in today advertising particularly strong.

Second, as immediate consequence of the previous mechanism, we note that in our model advertising is pro-cyclical as in real data. This is further confirmed by the fact that in all the shocks considered the advertising and output responses display the same sign at both the impact and during all the transition after the shock. This result is particularly appealing since it shows that our simple model is able to replicate the observed co-movements between advertising and GDP. In addition, this feature appears to be essentially independent from the value assigned to parameter $\gamma$. Indeed, we note that the response of advertising is positive as the output one, no matter which value we assigned to parameter $\gamma .{ }^{38}$

Third, the parameter $\gamma$ is instead crucial to isolate the aggregate effects of advertising expenditures. We note that under the market enhancing hypothesis (i.e. $\gamma \neq 1$ ), advertising operates as a mechanism that amplifies and propagates the effects of all stochastic shocks on consumption, output and hours worked. ${ }^{39}$ Not surprisingly, the effect is stronger the higher is the parameter $\gamma$. Conversely, under the spread demand around firms hypothesis $(\gamma=1)$, the effects of advertising on the aggregate dynamics are negligible. As we can see from the pictures, in this case the impulse response functions of all the main economic aggregates essentially coincide with the benchmark ones.

To understand the mechanism behind these results, it is important to bear in mind that in this model the parameter $\gamma$ is crucial for aggregate advertising being a determinant of labor and saving supplies. However, this happens only when the parameter $\gamma$ is different from 1. Indeed, we know that in such a case, aggregate advertising is an externality for consumers, since it does

\footnotetext{
${ }^{38}$ Consequently, with respect to this particular feature of the data, in our framework the hypothesis of advertising as market enhancing mechanism is observationally equivalent to the spread it around hypothesis.

${ }^{39}$ This is evident from the picture by comparing that variables' impulse response functions with the benchmark ones.
} 

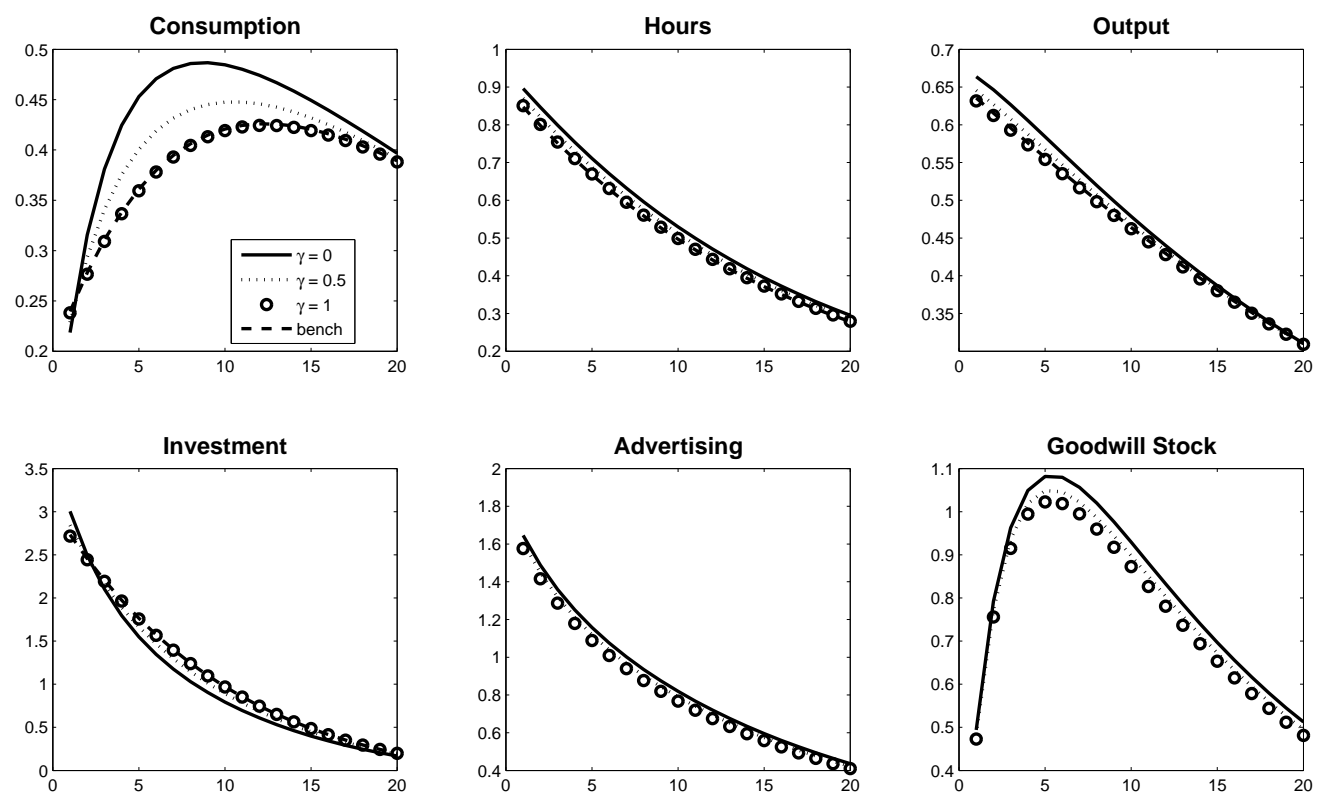

Figure 4: Impulse Response Functions to preferences shock. Each plot displays percent deviation from steady state of corresponding variable in response to a $1 \%$ decrease in the preference shock.

modify their own choices by affecting their consumption marginal utilities. Conversely, saving and labor supplies are not directly affected and all the equilibrium effects are driven by the excess of labor demand that results from the production of advertising expenditures. In such a case, the numerical analysis shows that the effects are negligible, since the pressure generated by the advertising resources absorbtion on the equilibrium prices are too modest in order to affect the other aggregates in a quantitatively relevant way. Hence, our model confirms the conjecture of Simon and Solow: under the spread it around hypothesis advertising is irrelevant in an aggregate perspective. By contrast, as long as $\gamma \neq 1$, advertising operates as an amplification mechanism that affects the behavior of consumption, output and labor. As far as the latter is concerned, we note that the excess of labor supply is so strong that the equilibrium level of hours worked increases even if the equilibrium wage rate is substantially lower than the benchmark one. ${ }^{40}$ This mechanism is the so called work and spend cycle (Schor (1992)) that has been already supported by several empirical works, like Brack and Cowling (1983) for U.S., and Fraser and Paton (2003) for UK. ${ }^{41}$

The dynamic behavior of consumption is particularly interesting. Compared with the benchmark model, we note that under the market enhancing hypothesis aggregate consumption displays a lower response at the impact of the shock, but a stronger hump-shaped impulse response function. As it was already argued, this suggests that with advertising the consumers faces a different intertemporal elasticity of substitution. To see the point it is useful to rewrite the log-linearized Euler Equation in terms of expected consumption growth, that is:

$$
E_{t}\left\{\Delta \widehat{c}_{t+1}\right\}=(1-\gamma) \eta_{c, g} E_{t}\left\{\Delta \widehat{g}_{t+1}\right\}+\frac{\eta_{c, p}}{\varepsilon} \frac{1}{\sigma} E_{t}\left\{\widehat{r}_{t+1}\right\}
$$

\footnotetext{
${ }^{40}$ To save space the wage impulse-response functions are not reported, but they are available from the authors upon request.

${ }^{41}$ See Molinari and Turino (2007) for further details.
} 

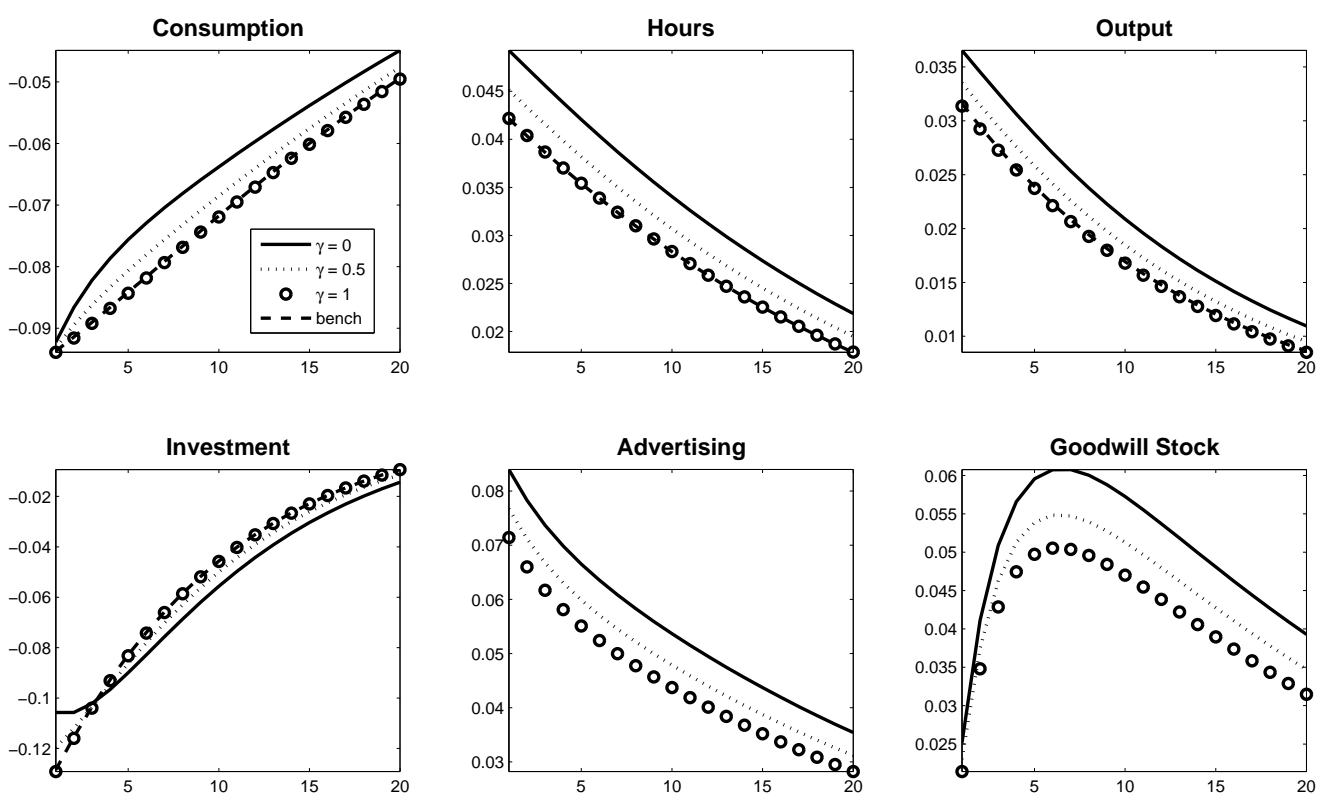

Figure 5: Impulse Response Functions to government spending shock. Each plot displays percent deviation from steady state of corresponding variable in response to a $1 \%$ shock on government spending.

where $\eta_{c, p}$ and $\eta_{c, g}$ are the steady state demand elasticity with respect to price and goodwill stock, respectively. Accordingly, aggregate advertising modifies the saving decision along two different intertemporal dimensions. On the one hand, since the elasticity $\eta_{c, g}$ is positive, expected variations in the aggregate goodwill stock modify directly and in the same direction the expected consumption growth. Intuitively, households correctly anticipate the effects that movements in this variable imply on the marginal evaluation of consumption, modifying accordingly the degree of consumption smoothness over time. In addition, the effect is stronger the lower is parameter $\gamma$. On the other hand, the elasticity of expected consumption growth to the real interest rate is lower than the benchmark one. This is true because with advertising the long run equilibrium is characterized by a lower aggregate price elasticity, $\eta_{c, p} \cdot{ }^{42}$ Thus advertising exerts on the saving function two opposite pressures whenever the responses of the interest rate and expected goodwill growth to an exogenous shocks have the same sign. The actual impact will obviously depends on the relative strengths of those different effects. ${ }^{43}$ The numerical analysis shows that the first effect dominates the second at the impact of the shock and during all the transition in which the goodwill displays a positive growth rate. This is confirmed by the behavior of aggregate investments. As we can see from the pictures, in all the cases considered the investment impulse-response is stronger than the benchmark one at the impact of the shock and up to the quarter in which the goodwill stock reaches its peak. ${ }^{44}$ This effect is particularly interesting because it shows that, contrary to the conventional wisdom, a positive link between aggregate consumption and advertising need not

\footnotetext{
${ }^{42}$ For a formal proof see Molinari Turino (2007)

${ }^{43}$ In addition, since the impulse response function of the goodwill stock is in general hump-shaped, during the all transition to the steady state the consumer experiences a time varying intertemporal elasticity of substitution. Accordingly, the sensitivity of saving function to the interest rate is not anymore constant as in the benchmark model.

${ }^{44}$ Note that in the case of government expenditures shock aggregate investment is less crowded out.
} 

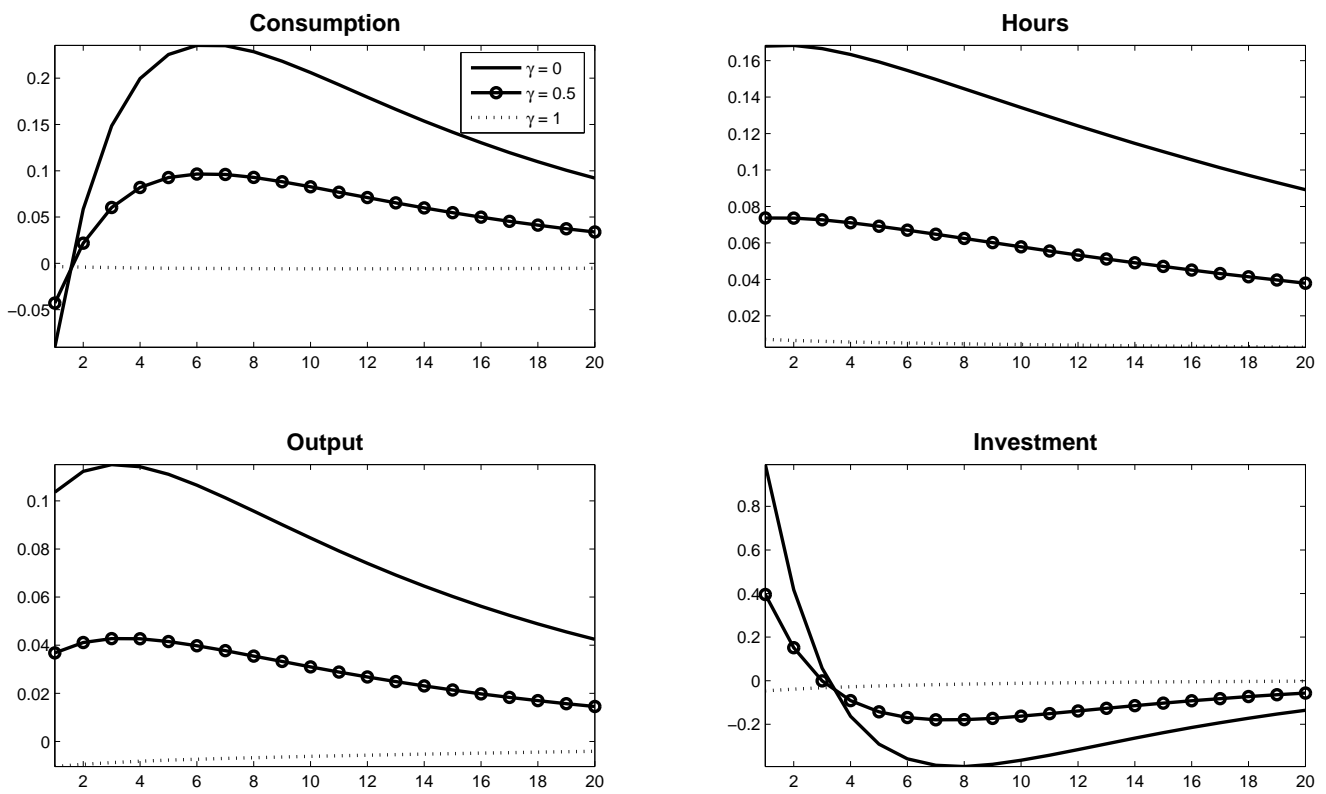

Figure 6: Impulse Response Functions to a shock on advertising production function. Each plot displays percent deviation from steady state of corresponding variable in response to a $1 \%$ shock on the production function of advertising.

to be necessarily associated with a crowding out effect on aggregate investment. On the contrary, once we account for the dynamic effect of advertising and, in particular, the effect on the labor supply, an equilibrium in which consumption, hours and investment all increase is instead possible, at least in the short run.

The larger availability of labor together with the behavior of consumption and investment generate a upward pressure on the aggregate demand. As a result, the equilibrium response of output to any shock considered is stronger than the benchmark one. Hence, our model confirms the conjecture of Kaldor such that advertising can potentially amplify the economic activity' fluctuations. However, this result is possible only if advertising affects directly the consumers' decisions $(\gamma \neq 1)$, otherwise the impact on total output is instead negligible.

Fifth, figure (6) shows that an unexpected increase in advertising productivity can affect the economy' fluctuations in a non trivial way. As we can see from the picture, a $1 \%$ increase in advertising productivity implies a positive response of all the main economic aggregates. Again, this result requires advertising being a determinant of both labor and saving supplies, otherwise the effects are negligible. Overall, this numerical experiment confirms once again that in our model advertising successfully affects the aggregate dynamics only when directly modifies the consumers' choices.

Finally, under the market enhancing hypotheses, advertising increases the fluctuations of the markup. Note that in a model with bounded marginal utility the markup is procyclical because the elasticity of the demand is inversely related to the output (i.e. higher output steeper demand). Now, according to equation (15) during booms firms advertise more because each unit of advertising yields higher marginal benefit. Thus, after a positive shock the goodwill increases, further reducing the elasticity of demand (see equation 14), and thus amplifying the response of the markup. The intuition is that with a higher level of advertising the consumer values more his consumption, and 

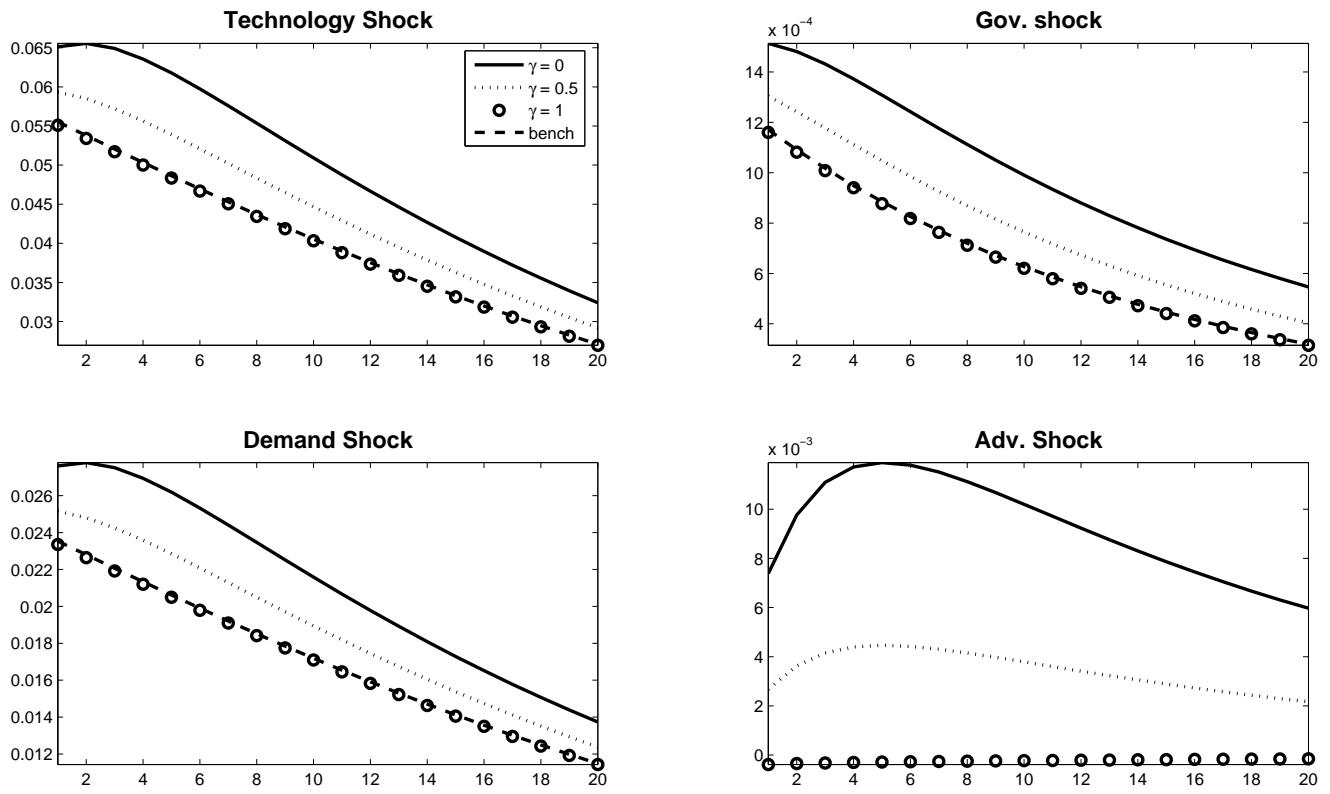

Figure 7: Impulse Response Functions of markup to all the shocks considered. Each plot displays percent deviation from steady state of corresponding variable in response to each shock.

firms exploit the consumer's higher willingness to pay for consumption by raising the markup.

\section{Welfare Analysis}

The impact of advertising on aggregate dynamics can be quantified comparing the welfare costs of fluctuations from this model with the ones from the associated benchmark economy without advertising. As usual in the literature on welfare, ${ }^{45}$ the costs of fluctuations are defined as the units of Steady State consumption that the consumer would be willing to pay to eliminate all the variability from his consumption stream. Such costs are computed as the difference between the $2^{\text {nd }}$ order Taylor approximated utility of the agent endowed with the equilibrium bundle $\left\{C_{t}, H_{t}\right\}$, and the approximated utility of an agent that gets in every period the steady state level of consumption and works the steady state amount of hours.

In case of welfare costs comparison between two economies endowed with different preferences relations, as the one we have here, several authors in the literature suggested to make a double comparison using both preference relations involved. ${ }^{46}$ However, we do not pursue such approach here because in our model the goodwill is an argument in the utility function, which implies that its variance biases the costs of fluctuations. To control for the effect of the goodwill it seems to us a more appropriate choice to consider only ex-ante preferences, i.e. to compute the welfare costs using the utility function from the benchmark economy. ${ }^{47}$

Table 5 reports the welfare costs of fluctuations in our model. We isolate the effect of advertising

\footnotetext{
${ }^{45}$ See Erceg Henderson and Levin (2000), or Otrok (2001).

${ }^{46}$ See Benhabib and Bisin (2002). This point is explained in details in Molinari and Turino (2007).

${ }^{47}$ In the literature on advertising, the preferences relation where advertising does not enter in the utility function is typically referred as ex-ante preference relation.
} 
by comparing the percent increase in the costs of fluctuations when switching from the benchmark economy without advertising to the model economy with advertising (percentages in parentheses in table 5). ${ }^{48}$ To check the robustness of our results, we use different calibrations for the two parameters that enter in the utility function, i.e. risk aversion $\sigma$ and Frisch elasticity of labor $\frac{1}{\phi}$.

\begin{tabular}{c|ccc}
\hline \hline \multicolumn{3}{c}{ Ex-ante preference relation, $\gamma=0$} \\
\hline \multicolumn{3}{c}{ Costs in percentage of SS consumption } \\
$\sigma$ & $\phi=0$ & $\phi=0.77$ & $\phi=3$ \\
\hline \multirow{2}{*}{1} & 0.044 & 0.008 & 0.001 \\
& $(53.8 \%)$ & $(25.3 \%)$ & $(17.7 \%)$ \\
2 & 0.171 & 0.047 & 0.021 \\
& $(63.4 \%)$ & $(23.6 \%)$ & $(16.4 \%)$ \\
5 & 0.247 & 0.11 & 0.079 \\
& $(145 \%)$ & $(75.8 \%)$ & $(42.3 \%)$ \\
\hline \hline
\end{tabular}

Table 4: Welfare costs of Fluctuations. In parentheses the percent increase in welfare costs from the benchmark model without advertising to the model with advertising and $\gamma=0$.

As apparent from table 5, when firms can advertise their goods the consumer is always willing to pay an higher percentage of his steady state consumption to get rid of fluctuations. The extra cost due to advertising ranges between $17,7 \%$ and $145 \%$, and worths $23 \%$ in the baseline calibration model.

\section{Model Estimation}

The model used in section 4.1 is estimated with Bayesian technique using macroeconomic time series quarterly data of U.S. economy. The sample goes from 1976:1 to 2006:2, i.e. the interval for which we have data on aggregate advertising (see section 2). Bayesian estimation is preferred among other estimation techniques for several reasons. First, in our model a crucial variable to estimate is the unobservable goodwill stock, and the maximum likelihood approach with the Kalman filter used to evaluate the likelihood is the more natural way to cope with unobservable variables. Second, the effects of advertising typically spreads in the economy through various transmission channels, which can be entirely assessed only once we compute the general equilibrium solution of the model. Therefore, any estimation that exploits only the information contained in partial equilibrium relationships, e.g. a GMM estimation of the Euler Equation, would neglect to consider some important information from the model.

Specifically, to estimate the model we proceed as follows. First, we derive the VARMA representation of the log-linearized model used in section $3:{ }^{49}$

$$
\widehat{x}_{t}=\Psi_{x}(\theta) \widehat{x}_{t-1}+\Psi_{\epsilon}(\theta) \epsilon_{t}
$$

where $\widehat{x}_{t}$ is the vector of partially latent endogenous variables ${ }^{50}$ in log-deviations from their steady state values, and $\Psi_{x}(\theta)$ and $\Psi_{\epsilon}(\theta)$ are matrixes containing the structural parameters of the model.

\footnotetext{
${ }^{48}$ We consider the economy with $\gamma=0$, which is the case where advertising has its strongest aggregate effect.

${ }^{49}$ See the appendix $\mathrm{C}$ for a detailed explanation of the model used in the estimation of the structural parameters.

${ }^{50}$ The vector of endogenous variables is defined in section 3.5
} 
Then, we add four measurements equations that links model variables to four key macroeconomic observable variables. In particular, we use log difference data of: real consumption, real output net of exports, total hours worked, and aggregate real advertising expenditures. ${ }^{51}$ The corresponding vector of measurement equations is:

$$
x_{t}^{*}=\left[\begin{array}{c}
d l C O N S_{t} \\
d l G D P_{t} \\
d l H O U R S_{t} \\
d l A D V_{t}
\end{array}\right]=\left[\begin{array}{c}
\bar{\tau} \\
\bar{\tau} \\
0 \\
\bar{\tau}
\end{array}\right]+\left[\begin{array}{c}
\hat{y}_{t}-\hat{y}_{t-1} \\
\hat{c}_{t}-\hat{c}_{t-1} \\
\hat{h}_{t}-\hat{h}_{t-1} \\
\hat{z}_{t}-\hat{z}_{t-1}
\end{array}\right]
$$

where $\bar{\tau}=\log (\tau)$ is the common quarterly growth rate trend, and $\tau$ is the theoretical deterministic trend of technology. Finally, using the state-space representation (22)-(23), the model structural parameters are estimated in order to maximize the likelihood of observed data conditional to our model or, in other words, choosing the vector $\theta$ that maximize the log posterior kernel of $\theta$ conditional to $x_{t}^{*} \cdot{ }^{52}$

In the estimated model the structure of shocks is slightly different from the one presented in section 3 because we shut down the shock on advertising and introduce a shock on the elasticity of the demand. This turns out to be a good estimation strategy to use jointly information from all the observable to identify all the parameters. The shock on the elasticity of the demand is usually interpreted in the literature a as a cost push shock on firms markup. Notice that once we shut down a shock we need to replace it because the estimated model must have a number of structural shocks equals the number of observable variables to which it is fitted. This is done to avoid the potential problem of singularity in the covariance matrix of forecast errors due to model mis-specification.

In the estimation we keep some parameters fixed, namely the discount rate $\beta$, the gross elasticity of demand $\epsilon$, the depreciation rate of capital $\delta_{k}$, the depreciation rate of the goodwill $\delta_{g}$, and the steady state value of the preference shock $\Xi$. The first three parameters are typically of difficult identification in RBC models, while $\delta_{g}$ turns out to be not identifiable separately from $\theta$. Finally, we fixed $\Xi$ because we are using data on worked hours in difference, which leaves undetermined the mean level of hours worked. Fixed parameters are calibrated according to the values in table (3).

All the other parameters, $\left\{\sigma, \phi, \alpha, \alpha_{z}, \theta, \bar{\tau}, \gamma, \rho_{a}, \rho_{h}, \rho_{f}, \rho_{m k}, \sigma_{a}, \sigma_{h}, \sigma_{i}, \sigma_{m k}\right\}$, are estimated combining the information from the likelihood of actual data $x_{t}^{*}$ with the one contained in the priors. Distributions for the priors are chosen according to what is used in the literature, while priors means are chosen such that steady states of model variables match selected long run moments of U.S. postwar data at priors means. Details are given in the tables (5) and (6):

In general our priors for the structural parameters are quite flat. The prior on $\theta$ is a gamma distribution (i.e. $\theta$ is bounded away from zero) with mean 2.50 and variance 0.4 . Given $\delta_{g}=0.3$, this value of $\theta$ implies a ratio of advertising over GDP equal to 0.02 , in line with the empirical evidence presented in section 2. The prior for $\gamma$ is an uniform $(0,1)$ distribution, which reflects our neutral stand between spread-it-around and market enhancing hypotheses. For the shocks processes we use very standard priors, following Smets and Wouters (2007), Chang Doh and Schorfheide (2006), and An and Schorfheide (2007).

Then, Bayesian estimation proceeds as follows. First, the posterior kernel is maximized in order to find the mode of the posterior distribution. Second, starting from a random perturbation around

\footnotetext{
${ }^{51} \mathrm{~A}$ detailed explanation of the data set is available in Appendix A.

${ }^{52}$ The $\log$ posterior kernel $\ln \mathcal{K}\left(\theta \mid x_{t}^{*}\right)$ is a linear combination between our prior knowledge about the distribution of $\theta, \ln p(\theta)$, and the log likelihood of $\theta$ conditional to the observed data, $\ln \mathcal{L}\left(\theta \mid x_{t}^{*}\right)$.
} 
Table 5: Prior Distributions of Structural Parameters

\begin{tabular}{cllcc}
\hline \hline Parameter & Density & Domain & Mean & $90 \%$ interval \\
\hline$\sigma$ & Gamma & $\mathbb{R}_{+}$ & 2.00 & {$[1.39,2.70]$} \\
$\phi$ & Gamma & $\mathbb{R}_{+}$ & 0.77 & {$[0.19,1.46]$} \\
$\theta$ & Gamma & $\mathbb{R}_{+}$ & 2.50 & {$[1.88,3.19]$} \\
$\gamma$ & Uniform & {$[0,1]$} & 0.5 & {$[0.10,0.90]$} \\
$\alpha$ & Beta & {$[0,1)$} & 0.75 & {$[0.68,0.81]$} \\
$\alpha_{\mathbf{z}}$ & Beta & {$[0,1)$} & 0.75 & {$[0.68,0.81]$} \\
$\bar{\tau}$ & Normal & $\mathbb{R}$ & .005 & {$[.0017, .0083]$} \\
\hline \hline
\end{tabular}

Table 6: Prior Distributions of Shock Processes

\begin{tabular}{cllcc}
\hline \hline Parameter & Density & Domain & Mean & $90 \%$ interval \\
\hline$\sigma_{\mathbf{y}}$ & InvGamma & $\mathbb{R}_{+}$ & .008 & {$[.001, .022]$} \\
$\sigma_{\mathbf{h}}$ & InvGamma & $\mathbb{R}_{+}$ & .034 & {$[.007, .096]$} \\
$\sigma_{\mathbf{f}}$ & InvGamma & $\mathbb{R}_{+}$ & .099 & {$[.020, .279]$} \\
$\sigma_{\mathbf{m k}}$ & InvGamma & $\mathbb{R}_{+}$ & .039 & {$[.008, .109]$} \\
$\rho_{\mathbf{y}}$ & Beta & {$[0,1)$} & 0.6 & {$[0.25,0.90]$} \\
$\rho_{\mathbf{h}}$ & Beta & {$[0,1)$} & 0.6 & {$[0.25,0.90]$} \\
$\rho_{\mathbf{f}}$ & Beta & {$[0,1)$} & 0.6 & {$[0.25,0.90]$} \\
$\rho_{\mathbf{m k}}$ & Beta & {$[0,1)$} & 0.6 & {$[0.25,0.90]$} \\
\hline \hline
\end{tabular}

the mode, a random walk Metropolis-Hastings algorithm is used to sample from the posterior distribution. ${ }^{53}$ We run this algorithm 4 times from different perturbations, eventually building 4 chains of 70,000 draws each. ${ }^{54}$ This strategy seems to assure relatively fast convergence of Markov chains generated from the algorithm, at least compared to what is usually reported in related literature. Convergence diagnostic indicates that around 40,000 drawings are enough to attain convergence for all the parameters. ${ }^{55}$

As last step, we report selected statistics for the posterior distributions by computing the correspondent moments from the Markov chains where we discard the initial $40 \%$ of observations from each chain. In tables (7) and (8) we report the mean and its $90 \%$ interval from posterior distributions. In Appendix C.3 we provide a set of figures with posterior and prior distributions for each parameter.

Our first concern is for the results of $\theta$ and $\gamma$, the two parameters related with advertising. The estimates seems quite informative, both posteriors have less variance than corresponding priors.

\footnotetext{
${ }^{53}$ The variance of the jumping distribution is the inverse of the Hessian from the maximization of the mode, multiplied by 0.35 . Acceptance rate is around $35 \%$. The initial perturbation is a single draw from a normal distribution with zero mean and variance equals to 5 times the variance of the jumping distribution. This larger variance helps to assure that together the chains visit the whole parameter space.

${ }^{54}$ As a robustness check, we have also estimated the model building 2 different chains of 500,000 draws each. We find that expending the length of draws does not affect our results. The results are however available from the authors upon request.

${ }^{55}$ See Appendix C.2 for details about the convergence diagnostic.
} 


\section{Table 7: Posterior Distributions of Structural Parameters}

\begin{tabular}{c|llrr}
\hline \hline \multirow{2}{*}{ Parameter } & Mean & Prior & \multicolumn{2}{c}{ Posterior } \\
\hline$\sigma$ & 2.00 & {$[1.39,2.70]$} & 2.48 & {$\left[\begin{array}{ll}1.87 & 3.08\end{array}\right]$} \\
$\phi$ & 0.77 & {$[0.19,1.46]$} & 2.52 & {$\left[\begin{array}{ll}1.76 & 3.37\end{array}\right]$} \\
$\theta$ & 2.50 & {$[1.88,3.19]$} & 2.62 & {$\left[\begin{array}{ll}1.96 & 3.27\end{array}\right]$} \\
$\gamma$ & 0.50 & {$[0.10,0.90]$} & 0.39 & {$[0.000 .76]$} \\
$\alpha$ & 0.75 & {$[0.68,0.81]$} & 0.67 & {$[0.610 .73]$} \\
$\alpha_{\mathbf{z}}$ & 0.75 & {$[0.68,0.81]$} & 0.73 & {$[0.690 .77]$} \\
$\bar{\tau}$ & .005 & {$[.0017, .0083]$} & .0035 & {$[.0031 .0041]$} \\
\hline \hline
\end{tabular}

Table 8: Posterior Distributions of Shock Processes

\begin{tabular}{c|clcc}
\hline \hline & \multicolumn{2}{c}{ Prior } & \multicolumn{2}{c}{ Posterior } \\
Parameter & Mean & $90 \%$ interval & Mean & $90 \%$ interval \\
\hline$\sigma_{\mathbf{y}}$ & .008 & {$[.001, .022]$} & .006 & {$[.0056 .0070]$} \\
$\sigma_{\mathbf{h}}$ & .034 & {$[.007, .096]$} & .019 & {$[.0146 .0248]$} \\
$\sigma_{\mathbf{f}}$ & .099 & {$[.020, .279]$} & .047 & {$[.0294 .0655]$} \\
$\sigma_{\mathbf{m k}}$ & .004 & {$[.008, .109]$} & .020 & {$[.0157 .0246]$} \\
$\rho_{\mathbf{y}}$ & 0.6 & {$[0.25,0.90]$} & 0.93 & {$[0.8860 .976]$} \\
$\rho_{\mathbf{h}}$ & 0.6 & {$[0.25,0.90]$} & 0.94 & {$[0.9170 .974]$} \\
$\rho_{\mathbf{f}}$ & 0.6 & {$[0.25,0.90]$} & 0.95 & {$[0.9260 .984]$} \\
$\rho_{\mathbf{m k}}$ & 0.6 & {$[0.25,0.90]$} & 0.83 & {$[0.7630 .903]$} \\
\hline \hline
\end{tabular}

The posterior mean of $\theta$ suggests that a value of 3 is a reasonable value for this parameter. This result supports the calibration used in Molinari and Turino (2007), and implies a ratio of advertising over GDP of $1,6 \%$ in the estimated model. This results is notable because it is obtained using data in first differences, therefore without using any information about the levels of advertising and output from the data.

The posterior mean of $\gamma$ is close to 0.4 , and the upper bound of 1 is significatively rejected from the data. ${ }^{56}$ This suggests that aggregate advertising is a significant explanatory variable of aggregate consumption, as conjectured in the market enhancing hypothesis. As a consequence, this estimation comfort the view that advertising affects the labor supply, as conjectured in Molinari and Turino (2007).

Among the other parameters, particular attention deserve the estimates of $\sigma$ and $\phi$. Means from posterior distributions of these parameters are relatively high compared with previous estimations in the literature, e.g. Smets and Wouters (2007), or with the calibrations typically used in the RBC

\footnotetext{
${ }^{56}$ We estimated several specifications of the model, in all of them estimates of $\widehat{\gamma}$ where significantly different from 1 , ranging in $\widehat{\gamma} \in(0.00,0.39)$.
} 
literature. In order to check this fact, we estimate a standard RBC model without advertising as benchmark, both using a utility function with the standard Dixit-Stiglitz aggregator, and the Bounded Marginal utility. The data set is the same used for the advertising model, and estimates for $\sigma$ and $\phi$ are reported in the table (9):

\begin{tabular}{l|cc|c}
\hline \hline Model & $\sigma$ & $\phi$ & $\begin{array}{c}\text { LogMarginal } \\
\text { DataDensity }\end{array}$ \\
\hline Dixit-Stiglitz & 1.55 & 2.48 & 1,312 \\
& {$[1.12,1.98]$} & {$[1.54,3.33]$} & \\
Bounded Marginal Utility & 1.88 & 2.65 & 1,314 \\
& {$[1.24,2.47]$} & {$[1.85,3.14]$} & \\
B.M.U. with Advertising & 2.48 & 2.52 & 1,530 \\
B.M.U. with Advertising & {$[1.86,3.07]$} & {$[1.76,3.37]$} & \\
restricted $\bar{\gamma}=1$ & 2.43 & 2.63 & 1,528 \\
\hline \hline
\end{tabular}

Table 9: Posterior Distributions for $\{\sigma, \phi\}$ in different models. 90\% confidence interval in parentheses.

While the evidence on $\phi$ are mixed, the ones on $\sigma$ clearly indicates higher estimates in the model with advertising. Our interpretation of this result relies on the effect of advertising on the marginal utility of consumption. Typically, in standard RBC model the estimation of $\sigma$ turns out to be low because the model predict an excess of consumption smoothing with respect to the data. In this model advertising is an argument in the utility function that co-moves with consumption, but has an opposite effect on the marginal utility. Therefore the effect of advertising on the volatility of the marginal utility offsets the one for consumption volatility, reconciling the evidence of constant marginal utility from the model with the volatile series of consumption.

Finally, the estimates of the parameters for the shocks processes are in line with the ones found in the empirical literature for similar DSGE models, e.g. Smets and Wouters (2007), suggesting that our model is able to treat the uncertainty present in the data with the same degree of accuracy than the one reported from similar model estimations in the literature.

In section 4.1 we made a point about the behavior of advertising in the model as a build-in mechanism of transmission of technology shocks to shifts in the aggregate demand. The variance decomposition from the estimated model is useful check our intuition. We plot variance decomposition from the estimated model with advertising against the variance decomposition from an estimated version of the model where advertising in banned.

Results from table (8) confirm our previous intuition. In the model with advertising technology shocks account for a bigger proportion of consumption, output, labor and investment volatility. In particular, once we introduce advertising in the model, technology shocks account for roughly $10 \%$ more of consumption volatility, and $17 \%$ more of output volatility than in the benchmark model without advertising, whereas the exogenous preferences shocks account for $15.3 \%$ less of consumption volatility, and around $15 \%$ less of output volatility. 


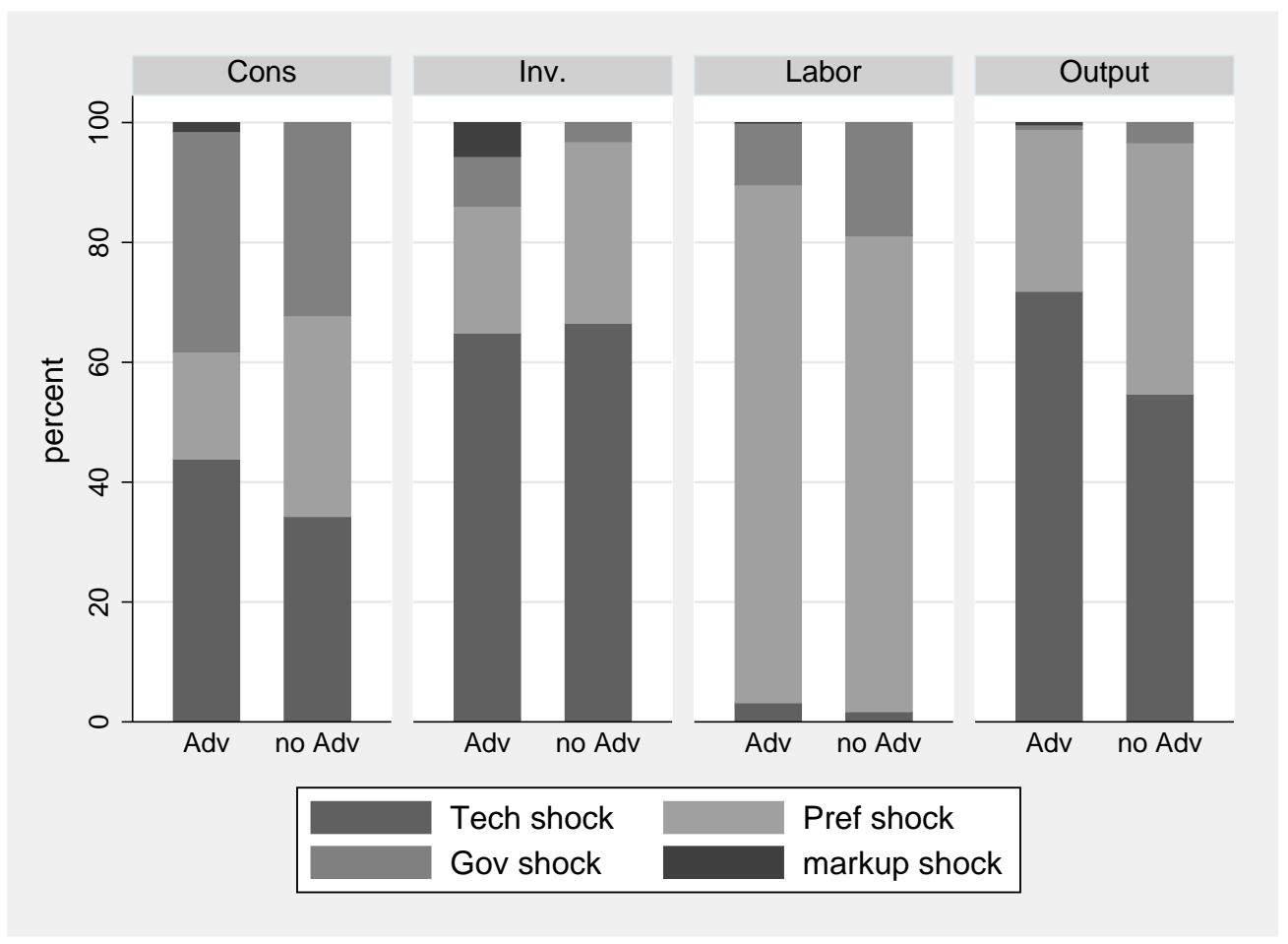

Figure 8: Total variance decomposition for selected variables.

\section{Conclusions}

In this paper we seek to understand the observed behavior of advertising over the business cycle, and its effect on aggregate dynamics. To this end, first we showed that actual U.S. data of aggregate advertising expenditures have a well-behaved pattern over the Business Cycle. Second, we build a model that can rationalize this pattern within the neoclassical growth models theory. Third, we show that a log-linearized version of the model can fit well actual data. Fourth, we show that under some conditions advertising can have a relevant impact on aggregate dynamics. Finally, we use an estimated version of the model to test whether these conditions hold. In our framework this is equivalent to test the spread-it-around against the market enhancing hypothesis as originally stated respectively by Solow (1968) and Galbraith (1958).

Our main finding is that the second hypothesis is preferred by the data. From an econometric point of view, this result hinges on the significance of aggregate advertising as explanatory variable of the volatility of aggregate consumption. This finding in turn implies that aggregate advertising enters in agents' choice about the desired level of consumption and labor, and we show that it has a non-negligible impact over the whole aggregate dynamics. Despite the modest size of the advertising industry over total production, i.e. roughly $2 \%$ of GDP in U.S., its short run impact on the business cycle turns out to be quantitatively important, exacerbating the welfare costs of fluctuations of $23 \%$ when going from an economy where advertising is banned to one economy where firms are free to advertise their products. Overall, the model goes in the direction suggested by Kaldor (1950): advertising amplifies aggregate fluctuations.

Also, we show that advertising has important effects on prices, affecting the behavior of the markup over the cycle. Since in our framework the optimal advertising policy is a positive function of the sales, and the price elasticity of the demand is a negative function of advertising, then the 
markup turns out to be procyclical. Moreover, its volatility is $20 \%$ higher when firms advertise than in the benchmark economy with no advertising.

It is worth noticing that our setup is the worst scenario to obtain any enhancing effect of advertising in the aggregate. In a model with nominal rigidities the consumer would further increase the supply of labor in response to new advertising because his wage varies less. This would strengthen the work and spend cycle mentioned above. Also, in a model with fully flexible prices as the one we use here, any increase of the markup due to advertising makes the investment goods more expensive, thus reducing the real return on capital, and in turns household savings. So, the general equilibrium effect of advertising on investment is negative, and partially offsets the positive effect on consumption from the work and spend mechanism, thus reducing the overall enhancing effect of advertising on the aggregate demand. ${ }^{57}$

Lastly, we show that advertising in this model behaves as an endogenous taste shock, with an intensity which is controlled by firms, and varies in the optimum whenever a technology shock occurs. This feature of the model leads to the observation that a shock to the productivity directly affects the aggregate demand through advertising. In fact, we find evidence that disregarding the advertising channel in a RBC model may lead to underestimate the effect of technology shocks in generating business cycle fluctuations.

\footnotetext{
${ }^{57}$ In an early draft of this paper we showed that in a two sectors model where consumption and investment are composed by different goods, advertising not only increases consumption, but also investment, since it lowers the relative price of investment goods. Thus, its overall effect on the aggregate demand was stronger than the ones presented in this paper.
} 


\section{A Sources of Data}

\section{A.1 Data on Advertising}

Advertising expenditures in TV, Cable, Radio, Magazines, and Outdoor:

Ad\$Summary, quarterly issues from 1976:1 to 2006:2, issued by Media Market New York City

Advertising expenditures in newspaper:

Newspaper Association of America. Data available on the official website of the Association: http://www.naa.org/

\section{Annual advertising expenditures and its components:}

Universal McCann, Robert Coen's Annual Report, Estimated Annual U.S. Advertising Expenditures from 1958 to 2006.

\section{A.2 Macroeconomic Data}

Source: Database "FRED II" of the Federal Reserve Bank of St. Luise available at the website: http://research.stlouisfed.org/fred2

Real Gross Domestic Product (GDPC96)

Real Exports of Goods \& Services (EXPGSC96)

Real Personal Consumption Expenditures (PCECC96)

Real Personal Consumption Expenditures: Durable Goods (PCDGCC96)

Real Personal Consumption Expenditures: Nondurable Goods: (PCNDGC96)

Real Private Fixed Investment (FPIC96)

GDP Implicit Price Deflator (GDPDEF)

Civilian Employment-Population Ratio (EMRATIO)

Civilian Non-Institutional Population (CNP160V)

\section{Source: Bureau of Labor Statistics}

Available at the website: http://www.bls.gov/data/home.htm

Total Private Average Weekly Hours of Production Workers (CES050007)

Total Non-farm Employment (CES050001)

Note: The series of worked hours used in the estimation is

$$
H=\frac{C E S 050007 * E M R A T I O}{168}
$$

where 168 normalizes weekly hours to agents' total endowment of hours in a week. Alternatively we use the series:

$$
H=\frac{C E S 050001}{C N P 160 V * 168}
$$




\section{B Technical Appendix}

\section{B.1 Firm's costs minimization problem}

To produce its good each firms employs two inputs, labor and capital, combined according to the following production function:

$$
y_{i, t}=A_{t} k_{i, t}^{1-\alpha}\left(\Gamma_{t} H_{p, t}(i)\right)^{\alpha}
$$

where $y_{i, t}, k_{i, t}, H_{p, t}(i)$, denote respectively firm's output, capital stock, and production-related labor. $A_{t}$ measures the stochastic technological progress of the Total Factor Productivity, and $\Gamma_{t}$ is the labor augmenting technological progress, which follows a deterministic trend, i.e. $\Gamma_{t}=\tau \Gamma_{t-1}$.

Firm's demand of production-related inputs is the solution to the dual problem of total cost minimization, given by $W_{t} h p_{i, t}+R_{t} k_{i, t}$, and subject to the production function constraint (24).

As result, firm's total cost function, and marginal cost are given respectively by:

$$
C T\left(y_{i, t}\right)=\frac{D}{A_{t}} W_{t}^{\alpha} R_{t}^{1-\alpha}\left(y_{i, t}\right)
$$

and

$$
\varphi_{i, t}=\frac{D}{A_{t}} W_{t}^{\alpha} R_{t}^{1-\alpha}
$$

where $D=\left(\frac{1-\alpha}{\alpha}\right)^{\alpha} \frac{1}{(1-\alpha)}$ is a positive constant.

Also, each firm promotes its sales by incurring in advertising expenditures. As in Grossmann (2007), we assume that advertising is produced by the marketing department of the firm using the following technology:

$$
z_{i, t}=A_{t} \Gamma_{t}\left(H_{a, t}(i)\right)^{\alpha} U_{t}^{z}
$$

where $z_{i, t}, H_{a, t}(i)$ denote respectively the new investment in advertising and the marketing-related labor. $U_{t}^{z}$ is a purely transitory idiosyncratic shock on advertising productivity.

\section{B.2 Profits maximization problem}

Each producer faces three demands for its product. One for consumption, i.e. (11), one for investment, and one for government purchases.

The demand function for investment goods derives from the solution to consumer's dual problem of expenditures minimization, subject to the technology constraint (6), i.e.

$$
i_{i, t}=\left(\frac{P_{i, t}}{P_{t}}\right)^{-\varepsilon} I_{t}
$$

About government's demand of goods, recalling the assumption that advertising does not affect government's choices, we can write it goods as the solution of the consumer's problem of expenditures minimization, subject to the constraint

$$
F_{t} \geq\left(\int f_{i, t}^{\frac{\varepsilon-1}{\varepsilon}}\right)^{\frac{\varepsilon}{\varepsilon-1}}
$$

where for simplicity we set the bound in utility to zero.

Thus, we can derive the total demand for good $i$ as

$$
y_{i, t} \equiv c_{i, t}+i_{i, t}+f_{i, t}=\left(\frac{p_{i, t}}{P_{t}}\right)^{-\varepsilon}\left(\tilde{C}_{t}+I_{t}+F_{t}\right)-B\left(g_{i, t}\right)
$$


where (30) uses (11) (29) and (28).

Then, firm's problem of profits maximization can be stated as choosing a sequences of prices $p_{i, t}$ and advertising-related labor $H_{a, t}(i)$ in order to maximize:

$$
\max _{\left\{H_{a, t}(i), p_{i, t}\right\}} E \sum_{t=0}^{\infty} Q_{0, t}\left(p_{i, t} y_{i, t}-C T\left(y_{i, t}\right)-W_{t} H_{a, t}(i)\right)
$$

subject to

$$
\begin{gathered}
g_{i, t}=z_{i, t}+\left(1-\delta_{g}\right) g_{i, t-1} \\
z_{i, t}=A_{t} \Gamma_{t}\left(H_{a, t}(i)\right)^{\alpha} U_{t}^{z} \\
y_{i, t}=\left(\frac{p_{i, t}}{P_{t}}\right)^{-\varepsilon}\left(\tilde{C}_{t}+I_{t}+F_{t}\right)-B\left(g_{i, t}\right)
\end{gathered}
$$

where $Q_{0, t}$ is the discount factor. $C T\left(y_{i, t}\right)$ is defined as in equation (25).

The first order conditions for an interior maximum of (31) are:

$$
\begin{gathered}
P_{i, t}=\frac{\varepsilon\left(1+\frac{B\left(g_{i, t}\right)}{y_{i, t}}\right)}{\varepsilon\left(1+\frac{B\left(g_{i, t}\right)}{y_{i, t}}\right)-1} \varphi_{t} \equiv \mu_{i, t} \varphi_{t} \\
\nu_{t}=\frac{W_{t}}{\alpha \Gamma_{t} U_{t}^{z} A_{t}} H_{a, t}(i)^{1-\alpha} \\
-\left(p_{i, t}-\varphi_{t}\right) B^{\prime}\left(g_{i, t}\right)+E\left[\left(1-\delta_{g}\right)\left(\nu_{t+1} Q_{t, t+1}\right)\right]=\nu_{t}
\end{gathered}
$$

\section{Estimation}

\section{C.1 The estimated model}

To ensure that the economy evolves along a balanced growth path we have to modify the consumers' preference. First, we assume that representative household derives utility from the object $\tilde{C}_{t}$ relative to the level of technology, $\Gamma_{t}$. That is, equation (1) is replaced with the following utility function:

$$
U\left(\tilde{C}_{t}, H_{t}\right)=E_{0} \sum_{t=0}^{\infty} \beta^{t}\left[\frac{\left(\tilde{C}_{t} / \Gamma_{t}\right)^{(1-\sigma)}-1}{1-\sigma}-\xi_{t} \frac{H_{t}^{1+\phi}}{1+\phi}\right]
$$

As in An and Schorfheide (2007), the term $\Gamma_{t}$ in the previous equation can be interpreted as an exogenous habit stock component. Second, we modify equation (19) as follows:

$$
B\left(g_{i, t}\right) \equiv \Gamma_{t}\left(S\left(g_{i, t}\right)+\gamma \int_{0}^{1}\left(1-S\left(g_{i, t}\right)\right) d i\right)
$$

where the function $S\left(g_{i, t}\right)$ is now defined as

$$
S\left(g_{i, t}\right) \equiv \frac{1}{1+\theta g_{i, t} / \Gamma_{t}}
$$


One can easily show that these assumptions, together with the assumed production functions, guarantee that existence of a balanced growth equilibrium in which all the endogenous variable growth a the same rate, $\tau$, with the exception of mark-up, interest rate and labor which are instead constant.

It is therefore convenient to express the model in terms of detrended variables, for which there exists a deterministic steady state. ${ }^{58}$ Let $\widehat{X}_{t}=X_{t} / \tau$ denote the ratio of a variable $X_{t}$ with respect to its deterministic trend, $\tau$. The model can be expressed as:

$$
\begin{aligned}
& \widehat{\widetilde{C}}_{t}=\widehat{C}_{t}+\frac{1+\gamma \theta \widehat{G}_{t}}{1+\theta \widehat{G}_{t}} \\
& \widehat{\tilde{C}}_{t}^{-\sigma}=\frac{\beta}{\tau} E_{t}\left[\widehat{\tilde{C}}_{t+1}^{-\sigma}\left(R_{t+1}+1-\delta_{k}\right)\right] \\
& \xi_{t} H_{t}^{\phi}=\widehat{W}_{t} \widehat{\tilde{C}}_{t}^{-\sigma} \\
& \widehat{W}_{t}=\alpha \mu_{t}^{-1}\left(\frac{\widehat{Y}_{t}}{H_{p, t}}\right) \\
& R_{t}=(1-\alpha) \mu_{t}^{-1}\left(\frac{\widehat{Y}_{t}}{\widehat{K}_{t-1}}\right) \tau \\
& \mu_{t}=\frac{\varepsilon_{t}\left(1+\frac{1+\gamma \theta \widehat{G}_{t}}{\left(1+\theta \widehat{G}_{t}\right) \widehat{Y}_{t}}\right)}{\varepsilon_{t}\left(1+\frac{1+\gamma \theta \widehat{G}_{t}}{\left(1+\theta \widehat{G}_{t}\right) \widehat{Y}_{t}}\right)-1} \\
& \left(1-\mu_{t}^{-1}\right) \frac{\theta}{\left(1+\theta \widehat{G}_{t}\right)^{2}}+E_{t}\left[\left(1-\delta_{g}\right) Q_{t, t+1} \nu_{t+1}\right]=\nu_{t} \\
& Q_{t, t+1}=\frac{\beta}{\tau}\left(\frac{\widehat{\tilde{C}}_{t+1}}{\widehat{\tilde{C}}_{t}}\right)^{-\sigma} \\
& H_{t}=H_{a, t}+H_{p, t} \\
& \nu_{t}=\frac{\widehat{W}_{t} H_{a, t}}{\alpha_{z} \widehat{Z}_{t}} \\
& \widehat{Z}_{t}=A_{t} H_{a, t}^{\alpha_{z}} \\
& \widehat{G}_{t}=\frac{\left(1-\delta_{g}\right)}{\tau} \widehat{G}_{t-1}+\widehat{Z}_{t} \\
& \widehat{K}_{t}=\frac{\left(1-\delta_{k}\right)}{\tau} \widehat{K}_{t-1}+\widehat{I}_{t}
\end{aligned}
$$

\footnotetext{
${ }^{58} \mathrm{An}$ equilibrium in which all the stochastic innovation are zero all the time.
} 


$$
\begin{gathered}
\widehat{Y}_{t}=\widehat{C}_{t}+\widehat{I}_{t}+\widehat{F}_{t} \\
\widehat{Y}_{t}=A_{t} \widehat{K}_{t-1}^{1-\alpha} H_{p, t}^{\alpha} \tau^{\alpha-1} \\
\log \left(A_{t}\right)=\rho_{a} \log \left(A_{t-1}\right)+\epsilon_{t}^{a} \\
\log \left(\xi_{t}\right)=\left(1-\rho_{h}\right) \log (\xi)+\rho_{h} \log \left(\xi_{t-1}\right)+\epsilon_{t}^{h} \\
\log \left(F_{t}\right)=\left(1-\rho_{f}\right) \log (F)+\rho_{f} \log \left(F_{t-1}\right)+\epsilon_{t}^{f} \\
\log \left(\varepsilon_{t}\right)=\left(1-\rho_{p}\right) \log (\varepsilon)+\rho_{p} \log \left(\varepsilon_{t-1}\right)+\epsilon_{t}^{p}
\end{gathered}
$$

where the exogenous shocks processes are assumed to satisfy: $\rho_{a}, \rho_{h}, \rho_{f}, \rho_{m k} \in[0,1)$ and

$$
\left(\begin{array}{c}
\epsilon_{t}^{a} \\
\epsilon_{t}^{h} \\
\epsilon_{t}^{f} \\
\epsilon_{t}^{p}
\end{array}\right) \sim N\left[\left(\begin{array}{l}
0 \\
0 \\
0 \\
0
\end{array}\right) ;\left(\begin{array}{cccc}
\sigma_{a}^{2} & 0 & 0 & 0 \\
0 & \sigma_{h}^{2} & 0 & 0 \\
0 & 0 & \sigma_{f}^{2} & 0 \\
0 & 0 & 0 & \sigma_{p}^{2}
\end{array}\right)\right]
$$

The system of equations (38)-(56) fully describes the model economy. Let $\hat{x}_{t}=\log \left(\widehat{X}_{t}\right)-$ $\log (X)$ denote the percentage deviation of the variable $\widehat{X}_{t}$ with respect to its deterministic steadystate. The VARMA representation of the model is determined by solving the linear system of first order stochastic difference equations obtained by log-linearized equations (38)-(56) around the deterministic steady-state:

$$
\widehat{x}_{t}=\Psi_{x}(\theta) \widehat{x}_{t-1}+\Psi_{\epsilon}(\theta) \epsilon_{t}
$$

where $\widehat{x}_{t}$ is a vector containing all the endogenous variables in percentage deviation with respect to its steady state, $\epsilon_{t}$ is a vector containing all the exogenous innovations, and $\Psi_{x}$ and $\Psi_{\epsilon}$ are matrixes whose entries are functions of the model structural parameters.

To estimate the model, the VARMA representation is augmented by adding four measurement equations that link model variables to four key macroeconomic observable variables. In particular, we use log difference data of: real consumption, real output net of exports, total hours worked, and aggregate real advertising expenditures. The corresponding vector of measurement equations is:

$$
x_{t}^{*}=\left[\begin{array}{c}
d l C O N S_{t} \\
d l G D P_{t} \\
d l H O U R S_{t} \\
d l A D V_{t}
\end{array}\right]=\left[\begin{array}{c}
\bar{\tau} \\
\bar{\tau} \\
0 \\
\bar{\tau}
\end{array}\right]+\left[\begin{array}{c}
\hat{y}_{t}-\hat{y}_{t-1} \\
\hat{c}_{t}-\hat{c}_{t-1} \\
\hat{h}_{t}-\hat{h}_{t-1} \\
\hat{z}_{t}-\hat{z}_{t-1}
\end{array}\right]
$$

where $\bar{\tau}=\log (\tau)$ is the common quarterly growth rate trend. Equations (57)-(58) form the statespace representation of the model economy through which the structural parameters are estimated in order to maximize the likelihood of observed data conditional to our model. 


\section{C.2 Convergence diagnostics for selected parameters}

Figures 9 and 10 plot the tests of convergence for our Markov chains. Following Gelman and Brooks (1998) section 3, we employ three criteria of converge for each parameter (i.e. univariate diagnostic):

Interval First column of figures 9 and 10. For each chain, take the $80 \%$ central interval of the draws from the simulation, compute the length of the interval over the parameter value, and form the mean of the interval lengths. This is the red line, i.e. the mean length of the within-chain intervals, calculated and plotted for increasing number of draws $n$. Then, from the whole set of draws gained from all the chains (280,000 draws), calculate the $80 \%$ central interval length. This is the blue line, i.e. the length of total-sequence interval, plotted for increasing number of draws $n$.

m2 Second column of figures 9 and 10. Repeat the same procedure, calculating the central second moment instead of the interval. Thus, the red line is the mean of central second moments, i.e. the mean of the variance of chains, while the blue line will be the total-sequence central second moment.

m3 Third column of figures 9 and 10. Repeat the same procedure as in m2, calculating the central third moment instead of the second moment.

Gelman and Brooks (1998) showed that in the three criteria the ratio between the two statistics goes to 1 as convergence is approached. Thus, we expect the blue and the red lines to stabilize and shrink to the same value for an increasing number of $n$ on the x-axis.
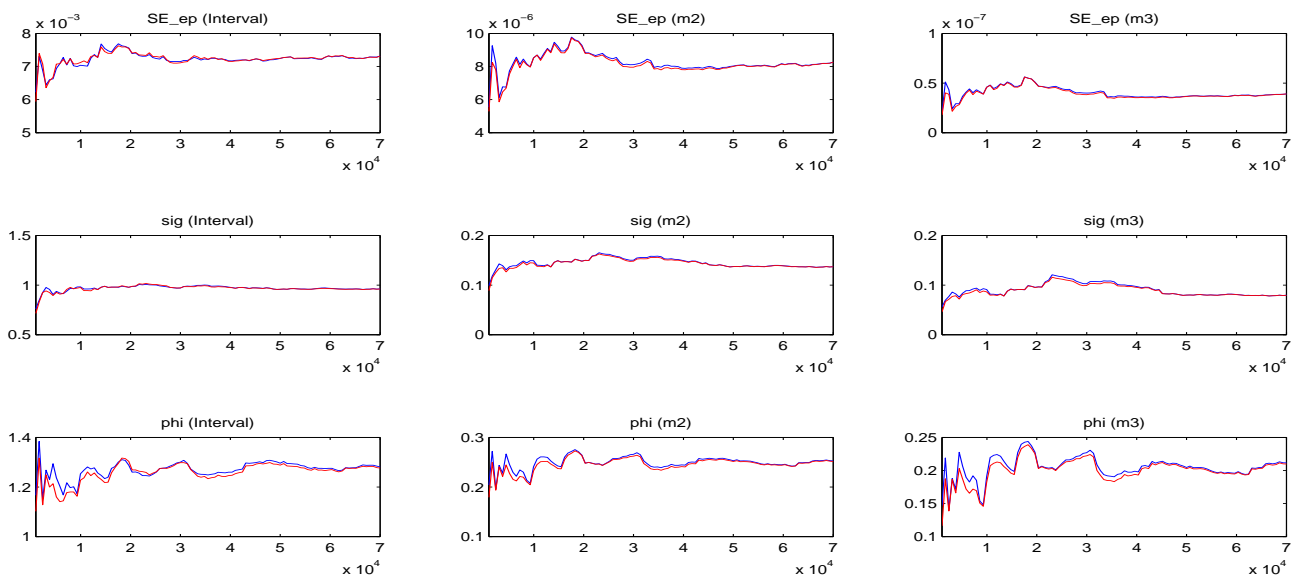

Figure 9: Gelman-Brooke Test 

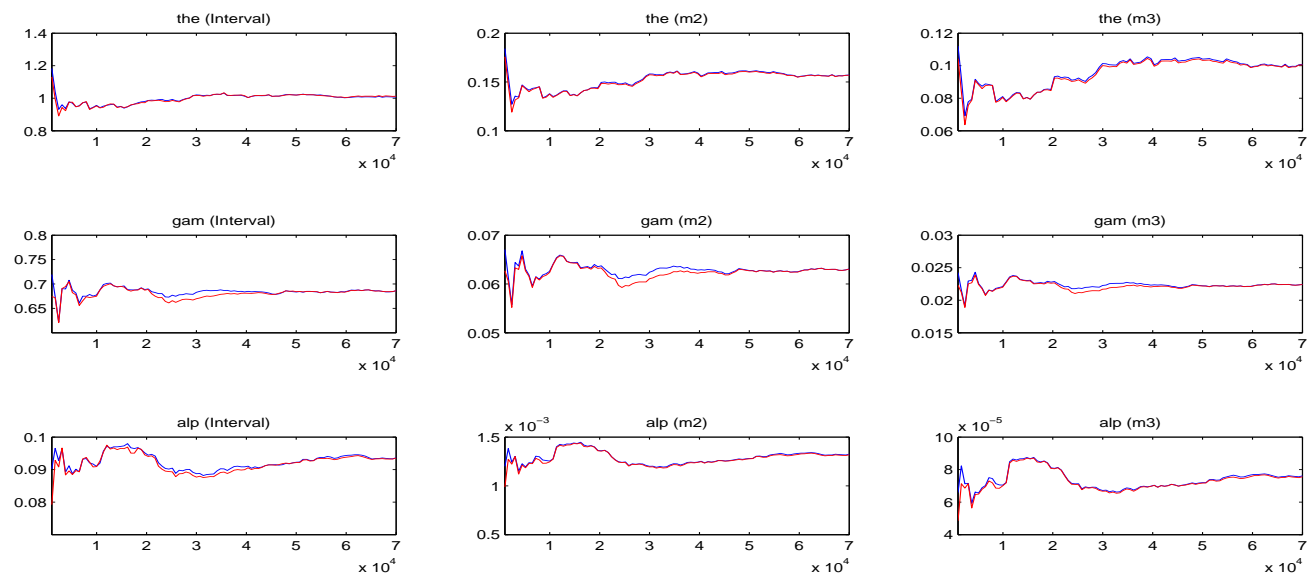

Figure 10: Gelman-Brooke Test
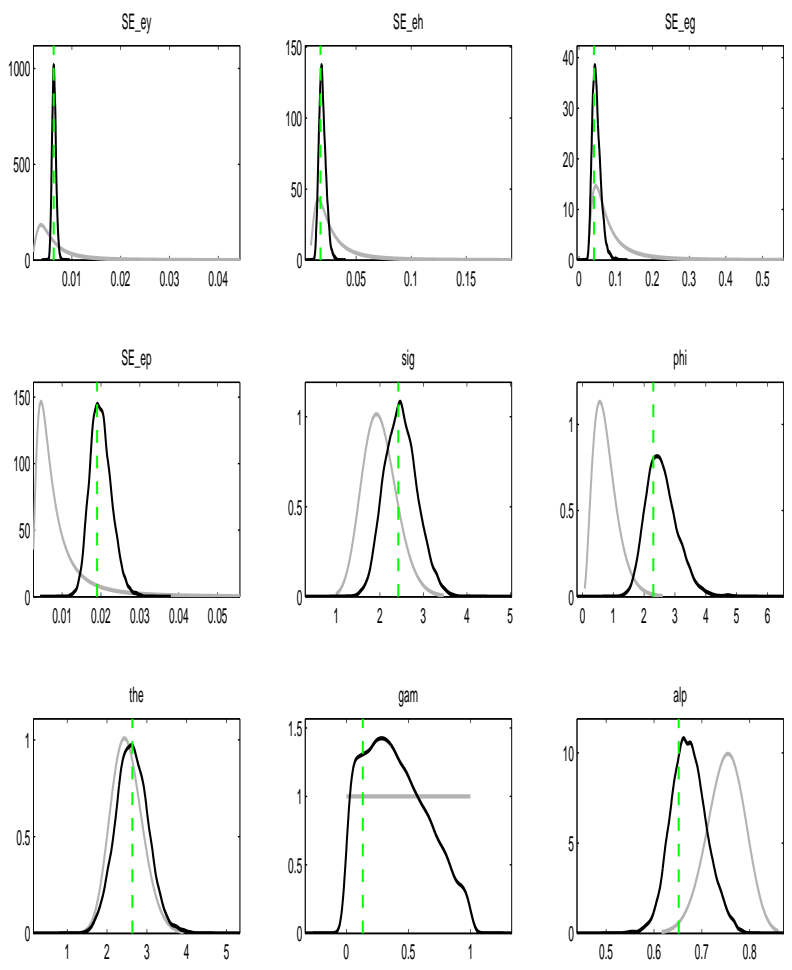

Figure 11: Priors and Posteriors distributions. Priors are plotted in gray, Posteriors in black, and the mode values computed to initiate the Chains are in dashed green. 

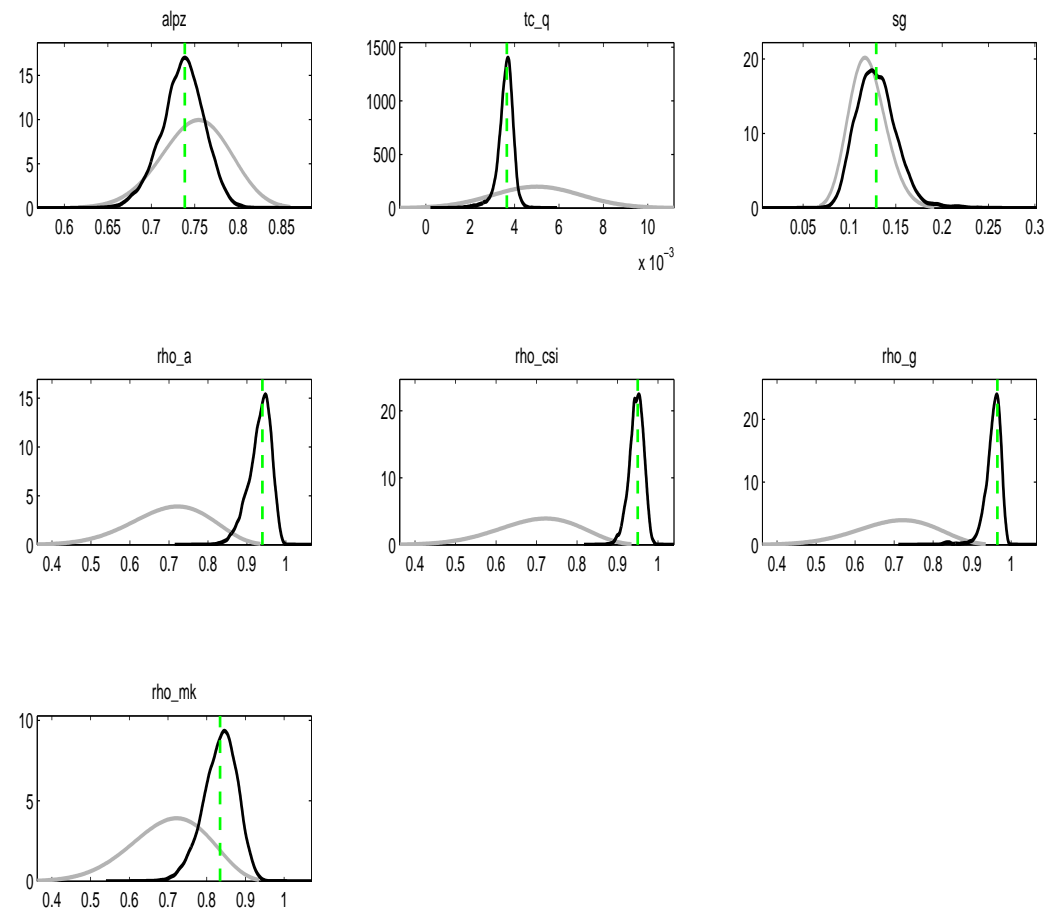

Figure 12: Priors and Posteriors distributions. Priors are plotted in gray, Posteriors in black, and the mode values computed to initiate the Chains are in dashed green. 


\section{References}

[1] An, Sungbae and Schorfheide, Frank (2007): "Bayesian Analysis of DSGE Models" Econometric Reviews vol. $26 \mathrm{n}^{\circ} 2-4$ pp. 113-172

[2] Ashley, R. and Granger, C.W.J. and Schmalensee R. (1980): "Advertising and Aggregate Consumption: An Analysis of Causality"; Econometrica vol. 48 n 5 pp.1149-1168.

[3] Bagwell, Kyle (2005): "The Economic Analysis of Advertising", Handbook of Industrial Organization, forthcoming

[4] Becker, Gary S. and Murphy, Kevin M. (1993): "A Simple theory of Advertising as a Good or a Bad", Quarterly Journal of Economics, vol. 108 n $^{\circ} 4$ pp. 941-964

[5] Benhabib, Jess and Bisin, Alberto (2002): "Advertising, Mass Consumption and Capitalism"; manuscript, Department of Economics NYU

[6] Benhabib, Jess and Wen, Yi (2004): "Indeterminacy, Aggregate Demand, and the Real Business Cycle"; Journal of Monetary Economics vol. 51 n 3 , pp. 503-530.

[7] Blank, David (1961): "Cyclical Behavior of National Advertising"; Journal of Business vol. 35 pp. 14-27.

[8] Brack, J and Cowling, K. (1983): "Advertising and Labor Supply: Workweek and Workyear in U.S. Manufacturing Industries, 1919-76"; Kyklos Vol. 36:2 pp.285-303

[9] Chamberlain, E.H. (1933): "The Theory of Monopolistic Competition"; Cambridge MA, Harvard University Press.

[10] Clarke, D. G. (1976): "Econometric Measurement of the Duration of Advertising Effect on Sales"; Journal of Marketing Research vol 13:4 pp. 345-357

[11] Collard, Fabrice and Harris Dellas (2006): "The case for inflation stability"; Journal of Monetary Economics, vol. 53(8), pp. 1801-1814

[12] Datamonitor (2004): "Advertising in The United States"; www.datamonitor.com

[13] Dixit, Avinash K. and Norman, Victor (1978): "Advertising and Welfare"; Bell Journal of Economics vol.9 $\mathrm{n}^{\circ} 1$ pp.1-17

[14] Dorfman, R. and Steiner, P.O. (1954). Optimal Advertising and Optimal Quality; American Economic Review vol. 44, n 5, pp. 826-836

[15] Erceg, Christopher J. and Anderson, Dale W. and Levin, Andrew T. (1978): "Optimal monetary policy with staggered wage and price contracts"; Journal of Monetary Economics vol.46 pp. 281-313.

[16] Fraser, J. and Paton, D. (2003): "Does advertising increases the labor supply? Time series evidences from the UK"; Applied Economics vol. 35, pp.1357-1368.

[17] Friedman, J.W. (1983): "Advertising and Oligopolistic Equilibrium", Bell Journal of Economics, 14, 464-73.

[18] Galbraith, J.K. (1958): "The Affluent Society", Boston, Houghton Mifflin. 
[19] Gelman, Andrew and Brooks, Stephen P. (1998): "General Methods for Monitoring Convergence of Iterative Simulations ", Journal of Computational and Graphical Statistics, vol. 7 N. 4, pp. $434-455$

[20] Jacobson, R. and Nicosia, F. M. (1981), "Advertising and public Policy: The macroeconomic effects of advertising", Journal of Marketing Research 17, 29-38.

[21] Jung C. and Seldom B. (1995), " The macro-economic relationship between advertising and consumption", Southern Economic Journal 62, 577-587.

[22] Kaldor, N.V. (1950): "The Economic Aspects of Advertising"; Review of Economic Studies vol.18 pp.1-27.

[23] Martin, S. (1993): "Advanced Industrial Economics", Oxford, Blackwell.

[24] Marshall, A. (1918): "Industry and Trade: A Study of Industrial Technique and Business Organization; and of Their Influences on the Conditions of Various Classes and Nations", MacMillan and Co. (London).

[25] Melitz, Marc J. and Ottaviano Giancarlo (2008): "Market Size, Trade, and Productivity"; Review of Economic Studies vol 75 pp 295-316

[26] Molinari, B. and Turino, F. (2007): "Advertising, Labor Supply, and the Aggregate Economy. A Long Run Analysis", Mimeo, Universitat Pompeu Fabra

[27] Nerlove, M. and Arrow, Kennet J. (1962): "Optimal Advertising Policy under Dynamic Conditions"; Econometrica vol. 29 pp. 129-142.

[28] Robinson, J. (1933): "Economics of Imperfect Competition"; MacMillan and Co. (London).

[29] Otrok, Christofer. (2001): "On measuring the welfare cost of business cycles"; Journal of Monetary Economics vol.47 pp.61-92.

[30] Ravn, Morten and Schmitt-Grohe, Stephanie and Uribe, Martin (2006): "Deep Habits", Review of Economic Studies vol. 73 pp. 195-218

[31] Schmalensee, Richard (1972), The Economics of Advertising, Amsterdam: North Holland.

[32] Schumpeter, J.A. (1939): "Business Cycles; A Theoretical Historical and Statistical Analisis of the Capitalist Process", McGraw-Hill, New York

[33] Simon, Julian L. (1970): "Issues in the economics of advertising", University of Illinois Press, Urbana (IL, U.S.A.)

[34] Solow, Robert (1968): "The truth further refined: a comment on Marris", The Public Interest vol. 11, pp. 47-52.

[35] Smets, Frank and Wouters, Raf (2007): "Shocks and frictions in US Business Cycles: A Bayesian DSGE Approach", American Economic Review, vol. 97 n. 3, pp. 586-606

[36] Tremblay, Victor (2005): "Advertising, Price, and Supermodularity", mimeo Oregon State University

[37] Yang, Y. C. (1964): "Variations in the cyclical behavior of advertising", Journal of Marketing $28: 2$ pp. 25-30. 


\section{PUBLISHED ISSUES $*$}

WP-AD 2008-01 "Service provision on a network with endogenous consumption capacity"

N. Georgantzis, C. Gutiérrez-Hita. March 2008

WP-AD 2008-02 “Capacity Restriction by Retailers”

R. Faulí-Oller. March 2008

WP-AD 2008-03 "The Role of the Interchange Fee on the Effect of Forbidding Price Discrimination of ATM Services”

R. Faulí-Oller. March 2008

WP-AD 2008-04 “Is Bundling Anticompetitive?”

I. Chioveanu. March 2008

WP-AD 2008-05 "Public Transfers to the poor: is Europe Really More Generous than the US?"

M.D.Collado, I. Iturbe, March 2008

WP-AD 2008-06 "Life-Cycle Portofolio Choice: The Role of Heterogeneity and Under- Diversification”

A. Campanale. March 2008

WP-AD 2008-07 "A New Approach for Bounding Awards in Bankruptcy Problems”

M. Jiménez, M.C. Marco. March 2008

WP-AD 2008-08 “Anti-Poverty Transfers without Riots in Tunisia”

C. Muller. May 2008

WP-AD 2008-09 "A multiobjective approach using consistent rate curves to the calibration of a Gaussian Heath-JarrowMorton model"

A. Falcó, Ll. Navarro, J. Nave. May 2008

WP-AD 2008-10 "Giving it now or later: altruism and discounting”

J. Kovarik. July 2008

\footnotetext{
* Please contact Ivie's Publications Department to obtain a list of publications previous to 2008.
} 
WP-AD 2008-11 "Specification Tests for the Distribution of Errors in Nonparametric Regression: A Martingale Approach" J. Mora, A. Pérez. July 2008

WP-AD 2008-12 "Optimal two-part tariff licensing contracts with differentiated goods and endogenous R\&D”

R. Fauli-Oller, J. Sandonis. September 2008

WP-AD 2008-13 "Estimating and forecasting GARCH volatility in the presence of outliers"

M.A. Carnero, D. Peña, E. Ruiz. October 2008.

WP-AD 2008-14 "Asset pricing in a general equilibrium production economy with Chew-Dekel risk preferences"

C. Campanale, R. Castro, G.L. Clementi. October 2008.

WP-AD 2008-15 "Framing effects in public goods: prospect theory ad experimental evidence”

I. Iturbe-Ormaetxe, G. Ponti, J. Tomás, L. Ubeda. December 2008.

WP-AD 2008-16 "A parametric control function approach to estimating the returns to schooling in the absence of exclusion restrictions: an application to the NLSY"

L. Farré, R. Klein, F. Vella. December 2008.

WP-AD 2008-17 "Second best efficiency in auctions"

A. Hernando-Veciana, F. Michelucci. December 2008.

WP-AD 2008-18 "The reliability of self-reported home values in a developing country context”

M. González, C. Quitana. December 2008.

WP-AD 2008-19 "Commuting costs and labor force retirement"

J. González. December 2008.

WP-AD 2009-01 "Does sex education influence sexual and reproductive behaviour of women? Evidence from Mexico"

P. Ortiz. February 2009.

WP-AD 2009-02 "Expectations and Forward Risk Premium in the Spanish Power Market"

M.D. Furió. February 2009. 
WP-AD 2009-03 "Solving the incomplete markets model with aggregate uncertainty using the Krusell-Smith algorithm"

L. Maliar, S. Maliar, F. Valli. February 2009.

WP-AD 2009-04 "Employee types and endofenous organizational design: An experiment”

A. Cunyat, R. Sloof. February 2009.

WP-AD 2009-05 “Quality of Life Lost Due to Road Crashes”

P. Cubí. February 2009.

WP-AD 2009-06 "The Role of Search Frictions for Output and Inflation Dynamics: A Bayesian Assessment”

M. Menner. March 2009.

WP-AD 2009-07 "Factors affecting the schooling performance of secondary school pupils - the cost of high unemployment and imperfect financial markets”

L. Farré, C. Trentini. March 2009.

WP-AD 2009-08 "Sexual orientation and household decision making. Same-sex couples' balance of power and labor supply choices"

S. Oreffice. March 2009.

WP-AD 2009-09 “Advertising and business cycle fluctuations"

B. Molinari, F. Turino. March 2009.

WP-AD 2009-10 "Education and selective vouchers"

A. Piolatto. March 2009.

WP-AD 2009-11 “Does increasing parents' schooling raise the schooling of the next generation? Evidence based on conditional second moments"

L. Farré, R. Klein, F. Vella. March 2009. 


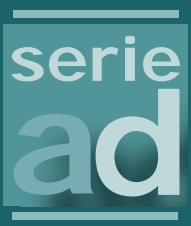

\section{I vie}

Guardia Civil, 22 - Esc. 2, 1 은

46020 Valencia - Spain

Phone: +34 963190050

Fax: +34 963190055

Department of Economics

University of Alicante

Campus San Vicente del Raspeig

03071 Alicante - Spain

Phone: +34 965903563

Fax: +34 965903898

Website: http:/ / www.ivie.es

E-mail: publicaciones@ivie.es 